\title{
Research Paper: The Effectiveness of Play Therapy Based on Cognitive-Behavioral Model: Behavioral Problems and Social Skills of Pre-School Children With Attention Deficit Hyperactivity Disorder
}

\author{
*Mohammad Ashori ${ }^{1}$, Fatemeh Dallalzadeh Bidgoli
}

1. Department of Psychology and Education of Children With Special Needs, Faculty of Education and Psychology, University of Isfahan, Isfahan, Iran 2. Department of Psychology, Faculty of Education and Psychology, University of Isfahan, Isfahan, Iran.

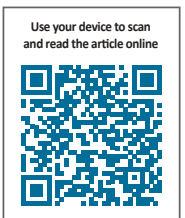

ditat on: Ashori M, Dallalzadeh Bidgoli F. [The Effectiveness of Play Therapy Based on Cognitive-Behavioral Model: Behavioral Problems and Social Skills of Pre-School Children With Attention Deficit Hyperactivity Disorder (Persian)]. Archives of Rehabilitation. 2018; 19(2):102-115. http://dx.doi.org/10.32598/rj.19.2.102

doi : http://dx.doi.org/10.32598/rj.19.2.102

Received: 09 Feb 2018

Accepted: 01 May 2018

Keywords:

Play therapy, Behavioral problems, So-

cial skills, Attention deficit hyperactivity disorder

\section{A B STRACT}

Objective Attention Deficit Hyperactivity Disorder (ADHD) is widely recognized as one of the most common neurodevelopmental disorders affecting children due to which they are frequently referred to clinics for their behavioral problems. Adding to their behavioral problems, many children with ADHD also have socialization with their parents, siblings and teachers. The long-lasting nature of ADHD easily results in social isolation. Thus, many children and adults with ADHD make few friends, even though they may desperately want to be liked. This can establish a vicious cycle in which they attempt to make new friends by latching onto people, with the least chance for interaction with others. It seems that play therapy could reduce behavioral problems and improve social skills of children with ADHD. The purpose of the present study was to investigate the efficacy of play therapy, based on the cognitive-behavioral model, on the behavioral problems and social skills of pre-school children with attention deficit hyperactivity disorder.

Materials \& Methods A semi-experimental study with pre-test and post-test design was conducted with 30 male participants, aged 5-6 years. These participants with ADHD were selected using an available method from the pre-school centers of Aran and Bidgol cities. The participants were divided into experimental and control groups, each group consisting of 15 children. The experimental group received 12 sessions of play therapy based on the cognitive-behavioral model while the control group did not have any sessions. The experiments were conducted using the Rutter child behavior questionnaire for parents (1975) and social skills rating scale of Gresham and Elliott (1990). Problem behavior questionnaires were completed by parents, and social skills rating scale was completed by teachers for all subjects during pre-test and post-test. Data collected before and after the training sessions were analyzed by multivariate analysis of covariance (MANCOVA) using the SPSS software V. 23.

Results Normality of variables and contingency of variance and covariance assumptions were tested. The Kolmogorov-Smirnov test showed that all variables were normal $(P>0.05)$. The Box test confirmed the contingency of variance-covariance assumption. The results of MANCOVA showed that play therapy based on the cognitivebehavioral model had a significant effect on the behavioral problems and social skills of children with attention deficit hyperactivity disorder $(\mathrm{P}<0.0001)$. It also had a significant effect on all the subscales of behavioral problems (aggression and hyperactivity, anxiety and depression, social maladjustment, antisocial behaviors, and attention shortage) and social skills (cooperation, self-assertiveness, and self-control) $(\mathrm{P}<0.0001)$ in these children. It can be stated that according to Eta square, $70 \%, 51 \%, 62 \%, 66 \%, 68 \%$, and $67 \%$ of variations in components such as aggression and hyperactivity, anxiety and depression, social maladjustment, antisocial behaviors, antisocial behaviors, attention shortage, and behavioral problems, respectively, can be explained by the subjects' participation in the play therapy program. Also, according to Eta square, $69 \%, 58 \%, 52 \%$, and $61 \%$ of variations in components such as cooperation, self-assertiveness, self-control, and social skills respectively, can be explained by the subjects' participation in the play therapy.

Conclusion Play therapy based on the cognitive-behavioral model can reduce behavioral problems and improve the social skills of children with attention deficit hyperactivity disorder. It is recommended that serious attention be paid while planning play therapy for children.

\section{* Corresponding Author:}

Mohammad Ashori, PhD

Address: Department of Psychology and Education of Children With Special Needs, Faculty of Education and Psychology, University of Isfahan, Isfahan, Iran.

Tel: +98 (31) 37932548

E-Mail: m.ashori@edu.ui.ac.ir 


\title{
اثربخشى بازى دومانى مبتنى بر مدل شناختى رفتارى بر مشكلات رفتارى و مهارتهاى اجتماعلى

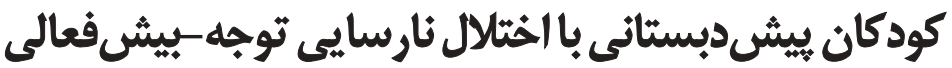

\author{
"محمد عاشورى' (1)، فاطمه دلالزاده بيدكلى'

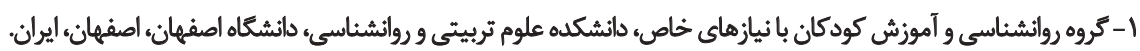

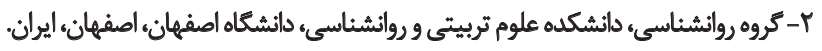

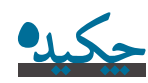

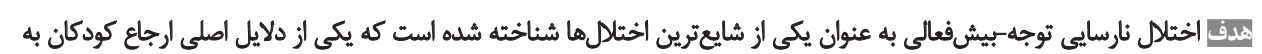

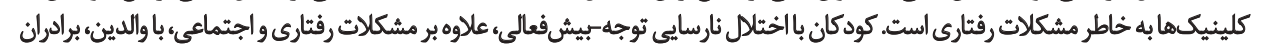

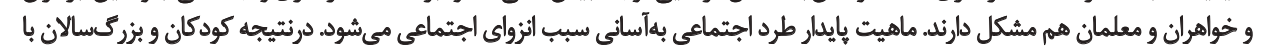

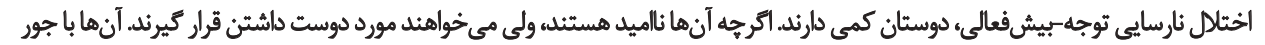

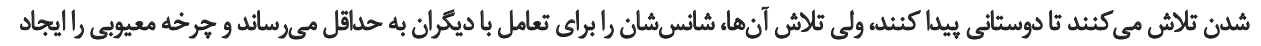

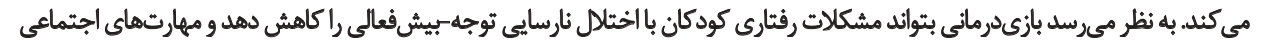

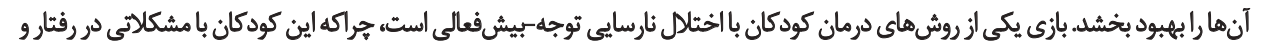

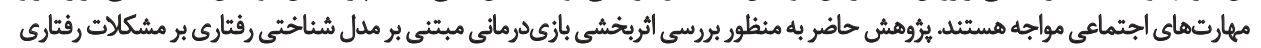

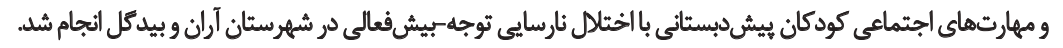

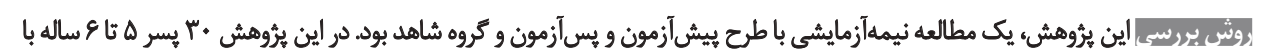

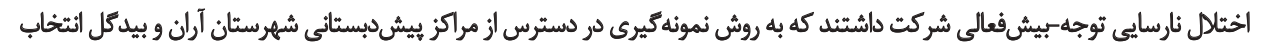

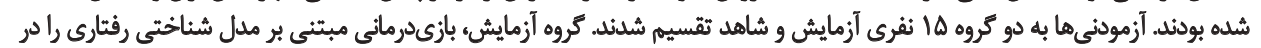

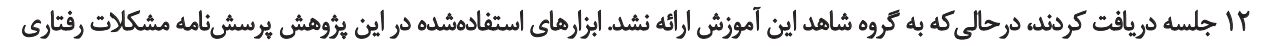

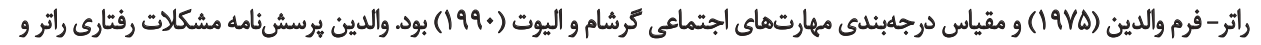

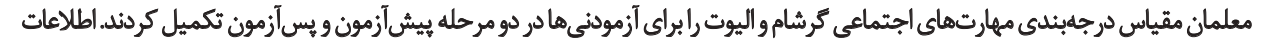

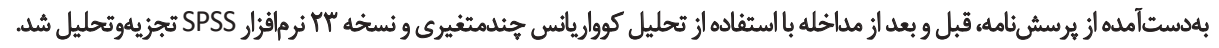

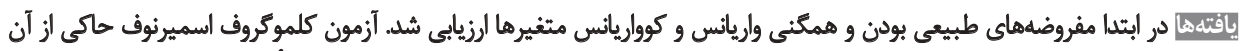

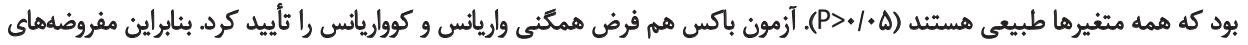

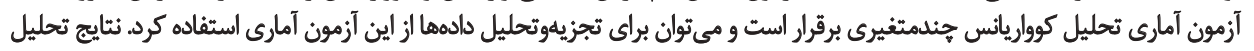

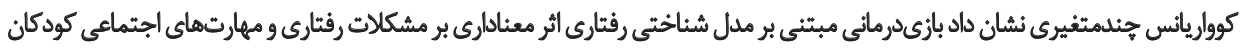

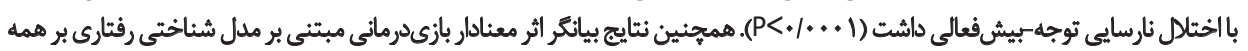

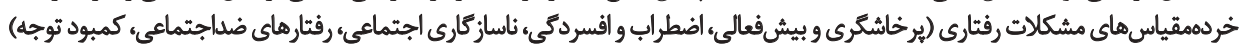

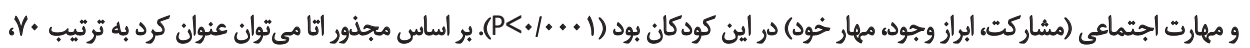

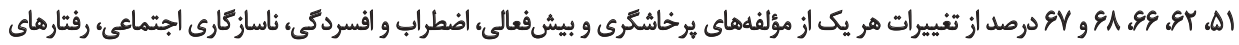

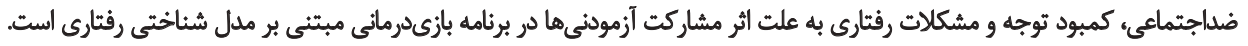

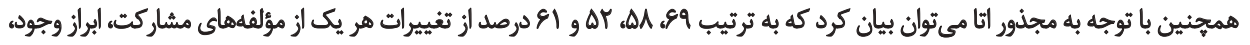

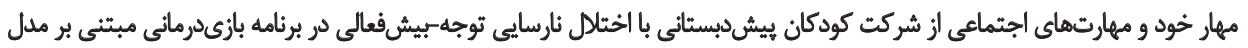

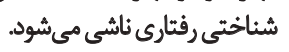

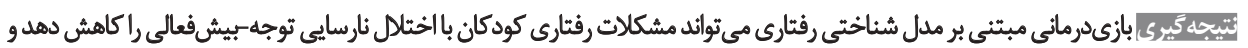

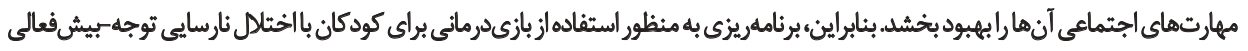
اهميت ويرماي الرد.
\end{abstract}

تاريخ دريافت: • بهيمين

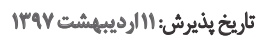


توجه-بيشفعالى به قدرى زياد است كه افراد در حال ثلاش

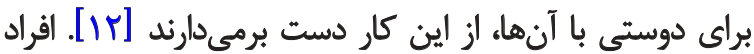

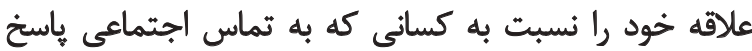

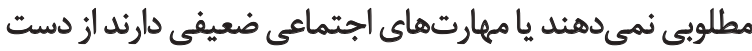

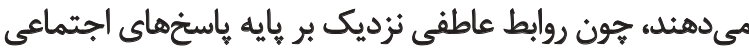

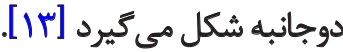

مهارتهاى اجتماعى كودكان با اختلال نارسايى توجه-

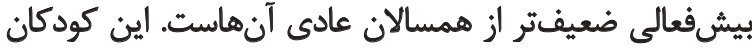

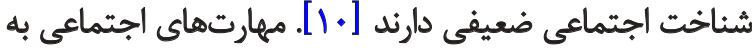

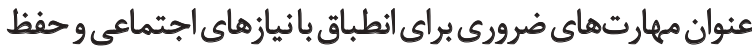

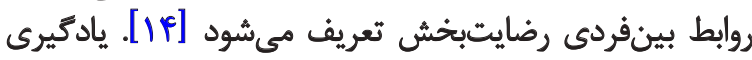

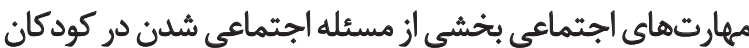

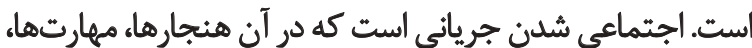

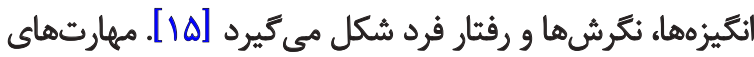

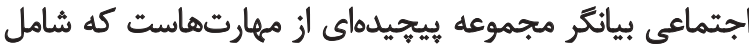

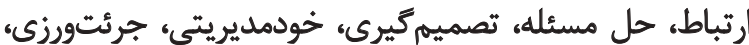
تعامل با همسالان و كروه ميشود [19] و و سه مؤلفه مشاركت،

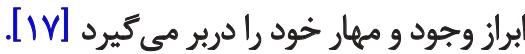
بيشتر كودكان در ارتباط با اطرافيان (والدين، خواهران، برادران

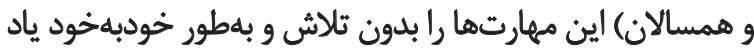

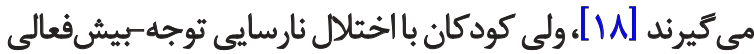

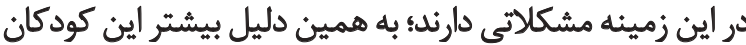

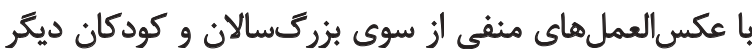

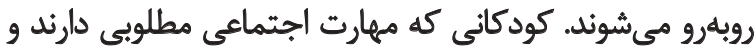

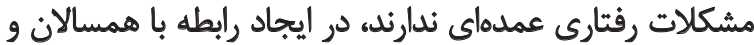

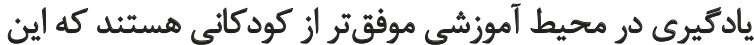

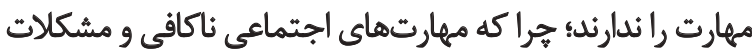

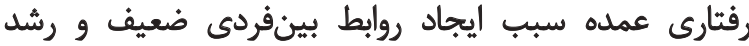

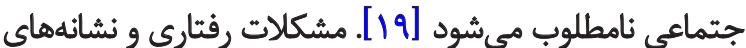

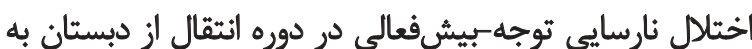

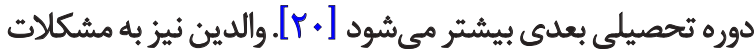

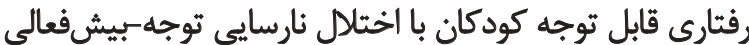

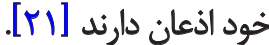

با توجه به اينكه عوامل مختلفى در مشكلات رفتارى و

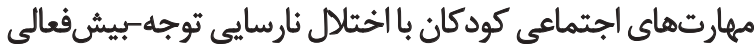

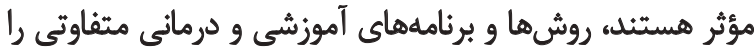

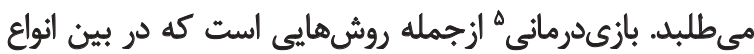

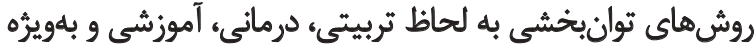

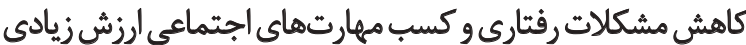

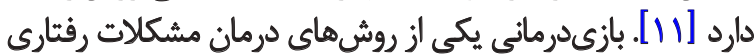
كودكان است كه دنياى درونى و بيرونى كودى راني را به همديكر
مقدمه

اختلال نارساييى توجه-بيشفعالى'، اختلال در بازدارى رفتار

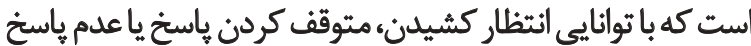

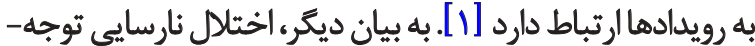

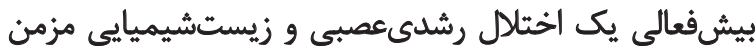

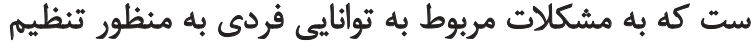

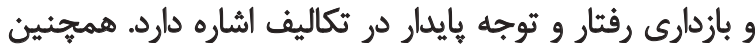

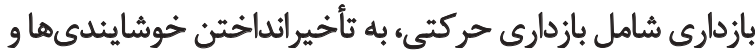

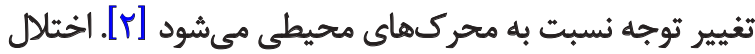

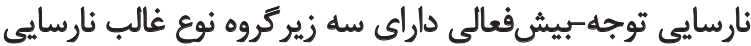

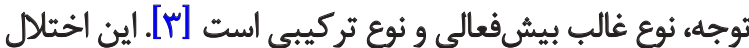

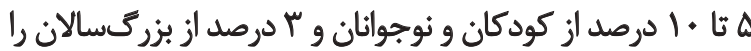

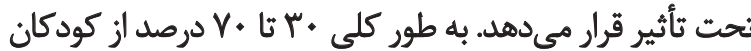

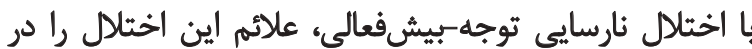

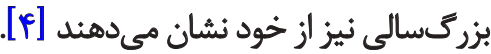

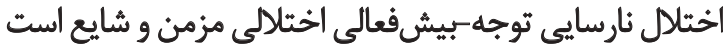

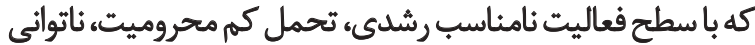

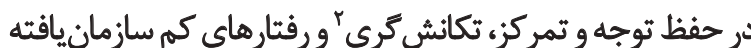

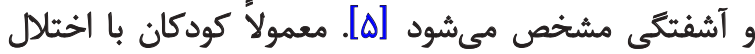

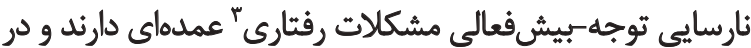

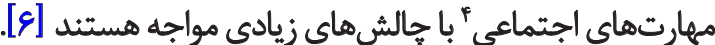

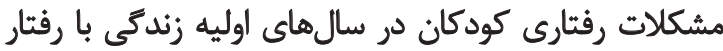

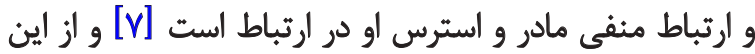

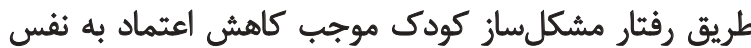

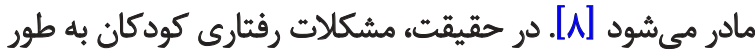

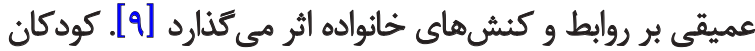

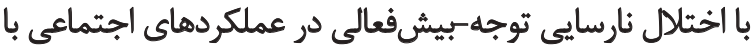

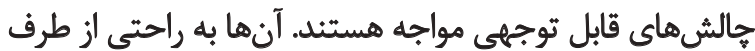

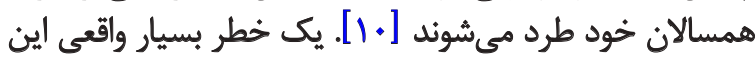

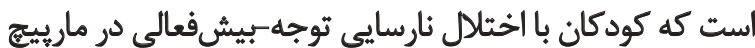

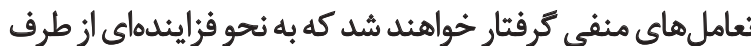

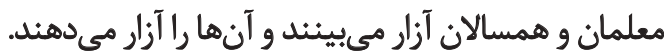

با توجه به نحوهاى كه ممكن است معلمان موجب رفتار

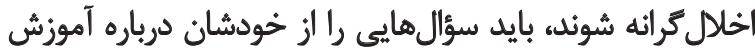

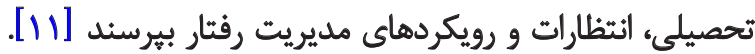

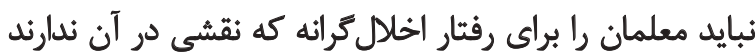

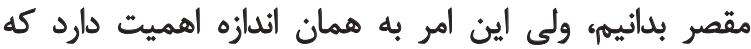

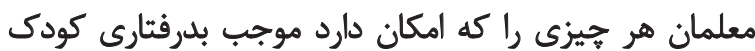
شود حذف كنئد. مشكلات رفتارى كودكان با اختلال نارسايى

\section{Attention Deficit Hyperactivity Disorder}

2. Impulsiveness

3. Behavioral problems

4. Social skills 
به مشاركت در كروه آزمايش را به طور معنادارى افزايش داد.

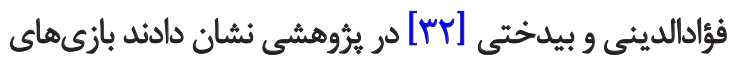

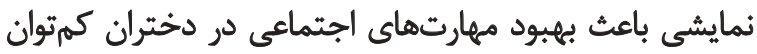

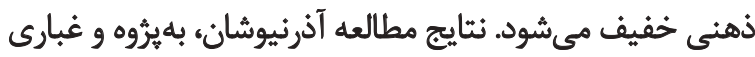

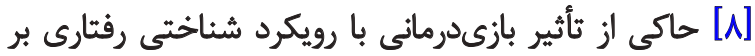

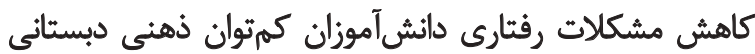

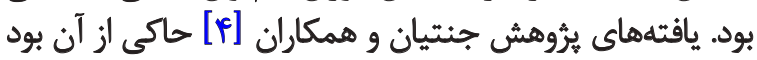

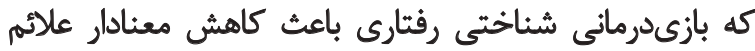

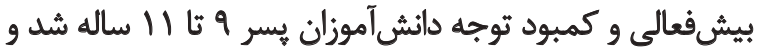
مشكلات رفتارى آنها كاهش يافت تئت

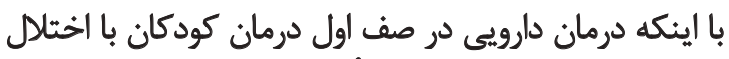

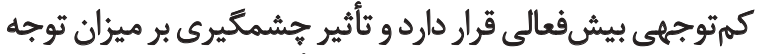

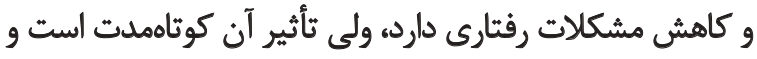

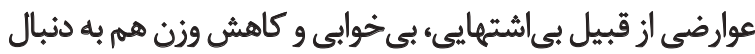

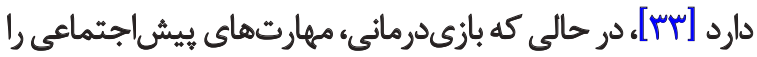

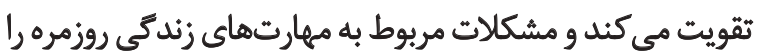

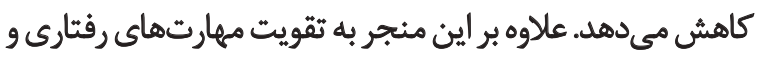

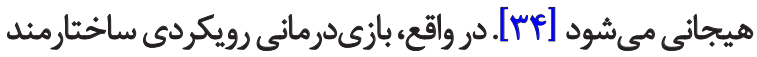

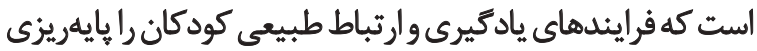

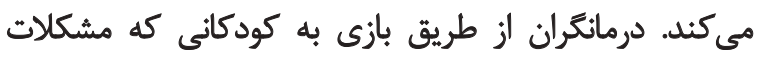

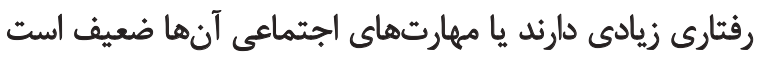

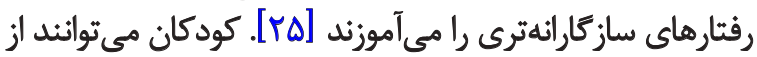

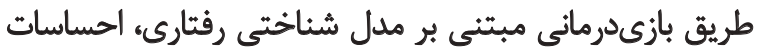

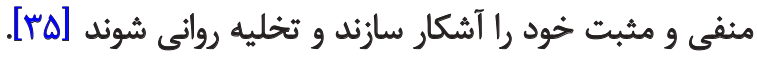

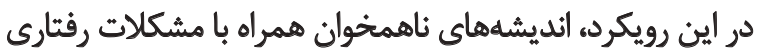

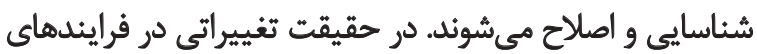

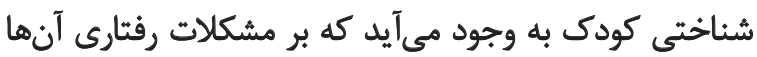

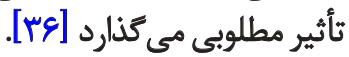

از آنجايى كه كودكان با اختلال نارسايى توجه-بيشفعالى

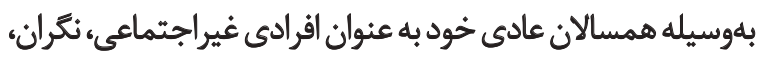

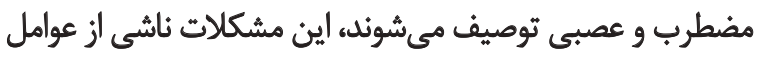

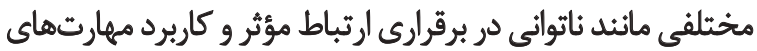

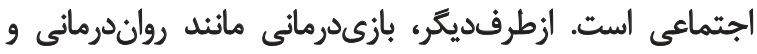

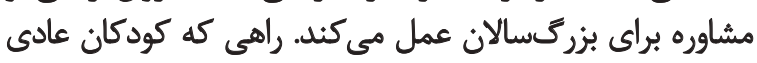

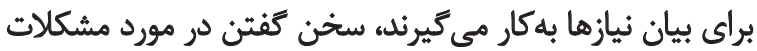

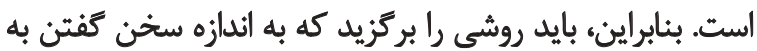

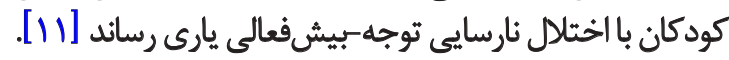

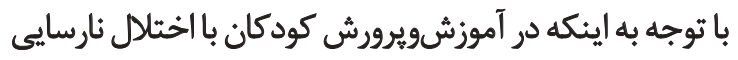

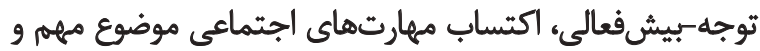

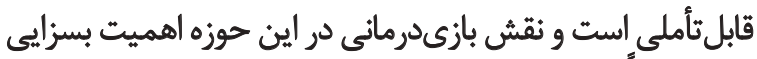

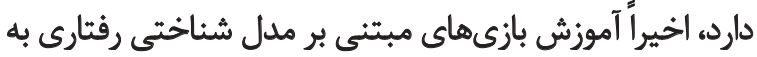

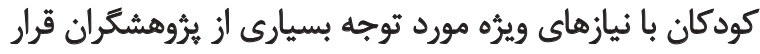

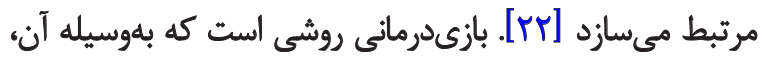

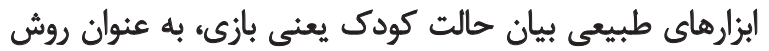

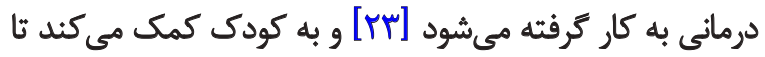

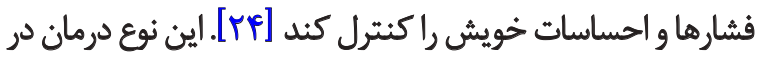

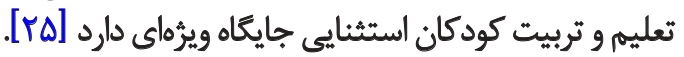
در بازىدرمانى از رويكردهاى مختلفى استفاده مىشود كه

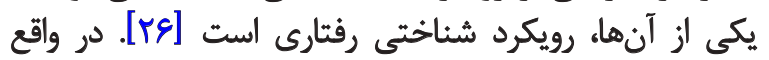

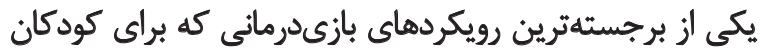

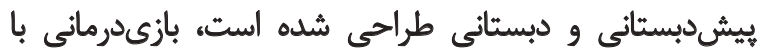

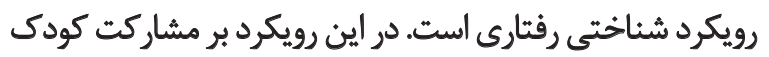

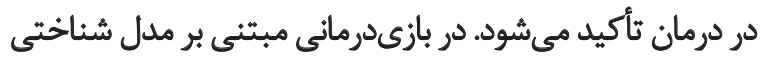

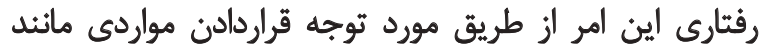

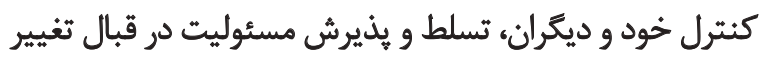

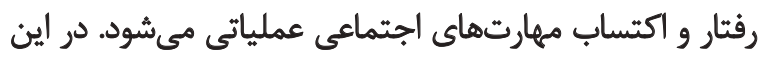

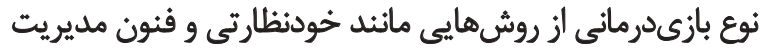

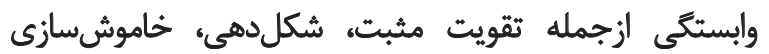

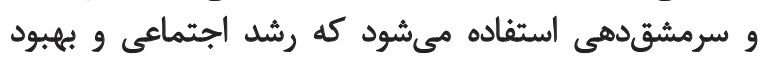

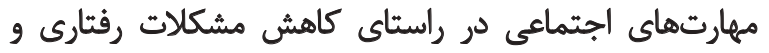
سازكارى ازجمله اهداف نهايى آن است [rهائ.

در سال هاى اخير، بهبود مهارت اجتماعى و كاهش مشكلات

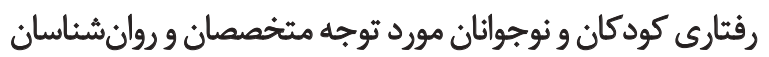

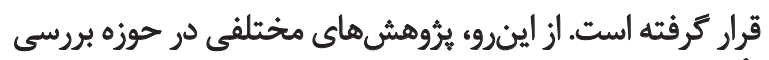

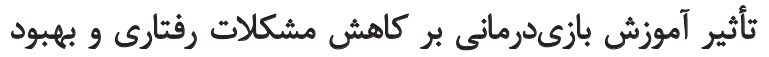

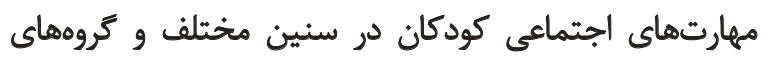

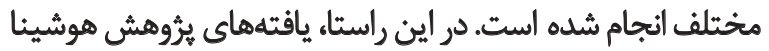

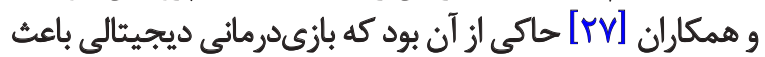

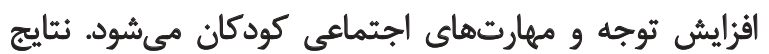

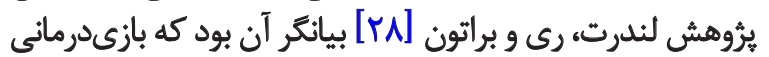

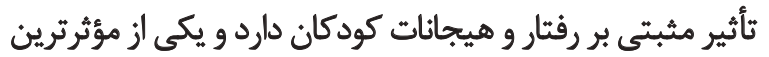

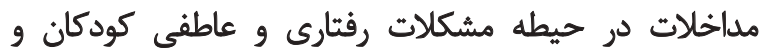

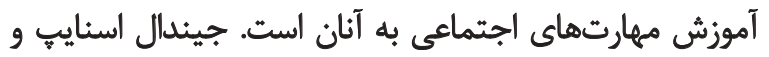

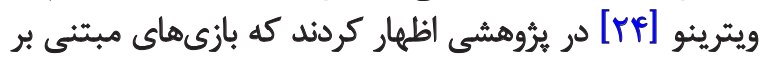

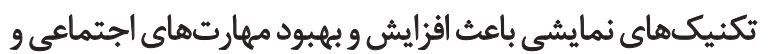

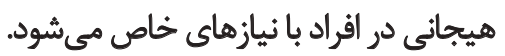

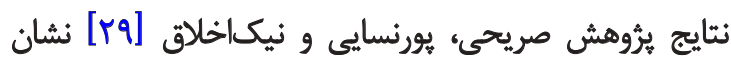

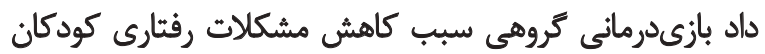

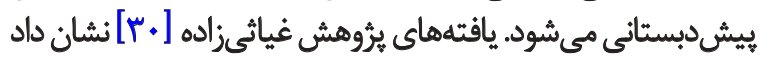

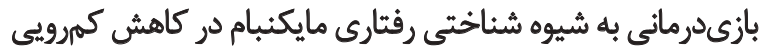

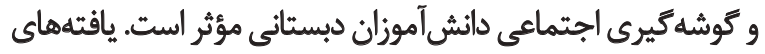

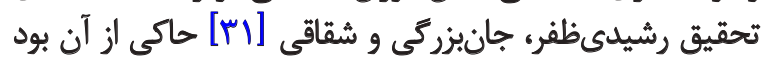

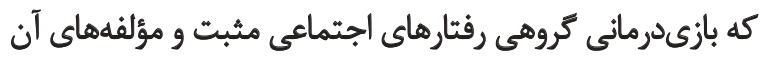

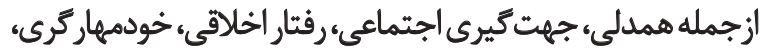

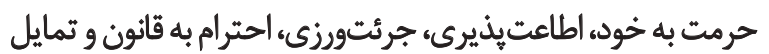


صورت ئذيرفت. ملاكهاي ورود به يُروهش شامل داشتن اختلال

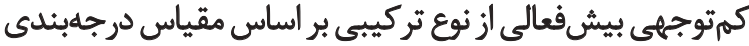

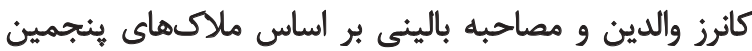

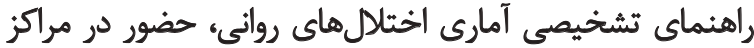

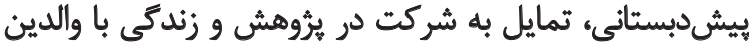

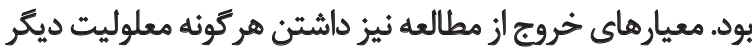

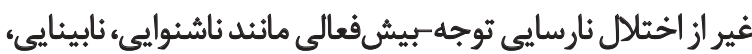

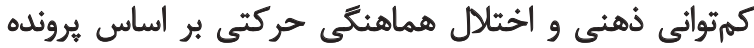

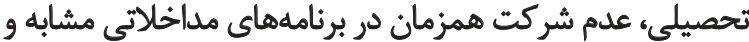

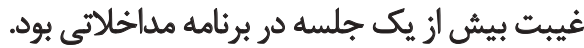

براى جمعآورى اطلاعات از ابزارهاى زير استفاده شد:

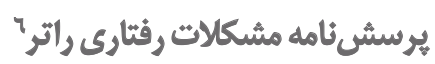

از اين مقياس براى ارزيابى مشكلات رفتتارى كودكان استفاده

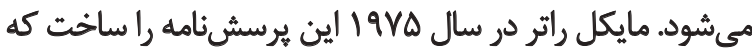

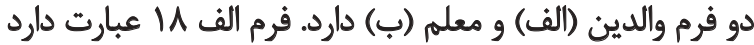

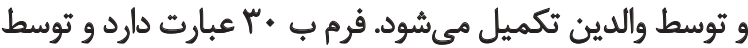

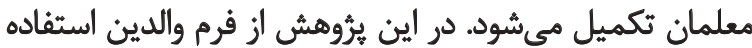

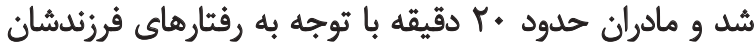

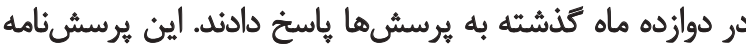

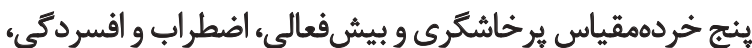
ناساز كارى اجتماعى، رفتار هاى ضداجتمائماعي، و كمبود توجه دارد. نمرهذذارى به صورت لاصفر: اصلأ درست نيسته"، لا: درست

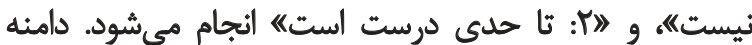

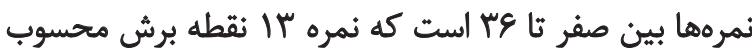

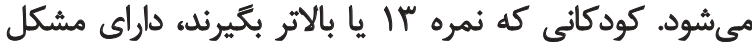

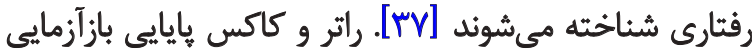

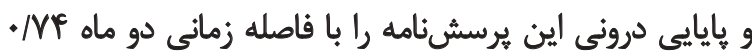

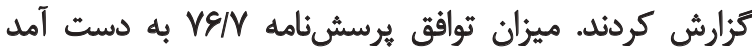

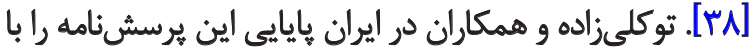

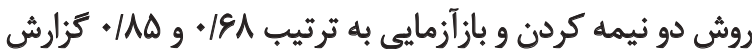

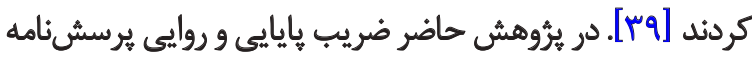

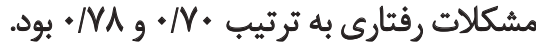

\section{مقياس درجهبئدى مهارتهاي اجتماعى v}

كرشام و اليوت در سال •199 اين مقياس را ساختند كه

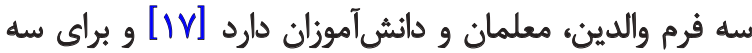

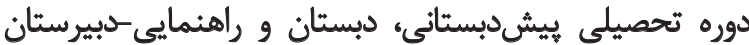

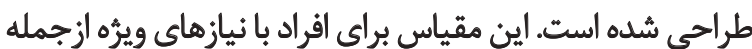

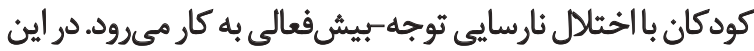

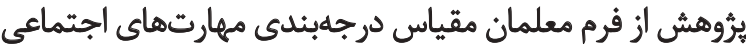

كرفته است كه حاكى از خلأ يروهشى در اين حوزه است. به نظر مىرسد كه يرؤهشهاي داخلى اندكى در اين زمينه

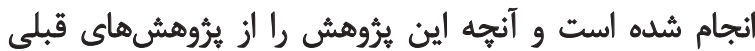

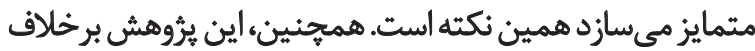

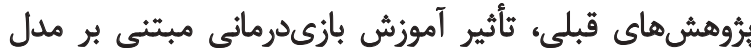

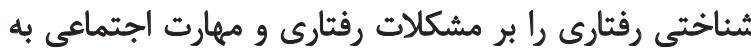

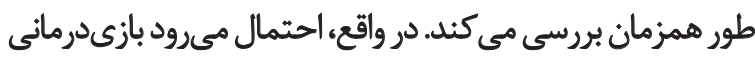

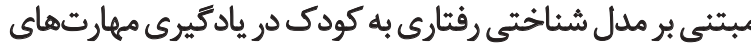

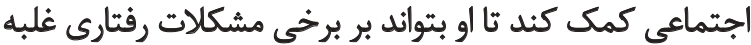

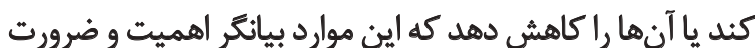

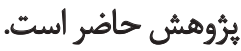

علاوه بر اين، دور از انتظار نيست كه آموزش بازىهاى مبتينى بر

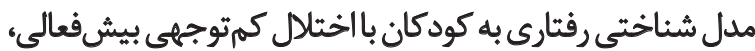

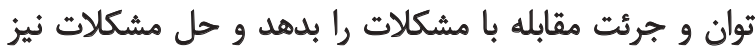

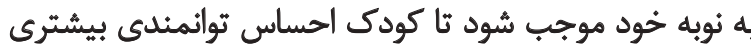

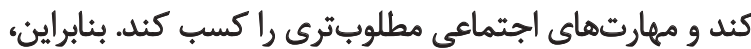

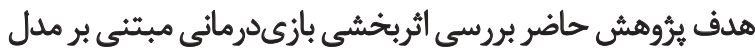

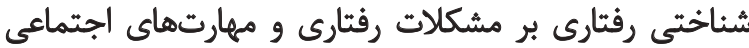

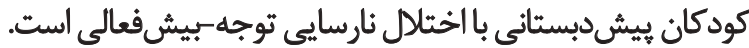

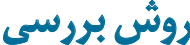

در اين برُوهش كه از نوع مطالعات نيمهآزمايشى است، از طرح

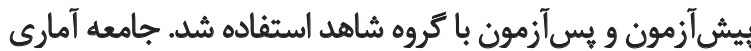

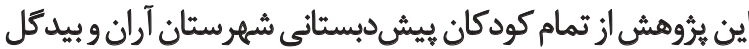

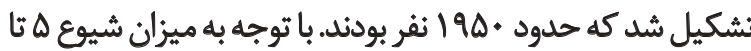

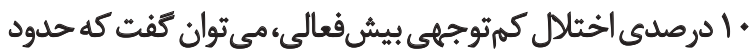

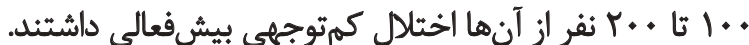

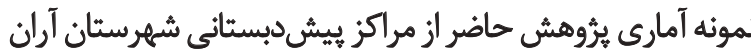

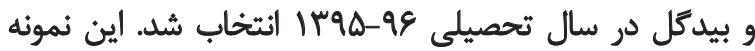

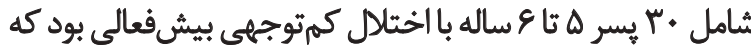

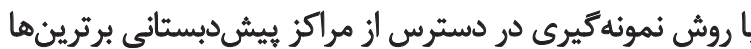

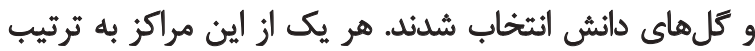

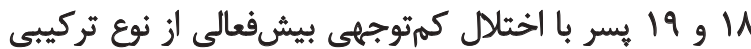

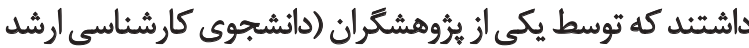

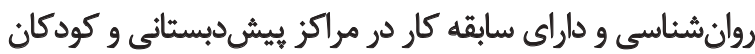
بيشفال) تشخيص داده شد.

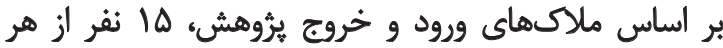

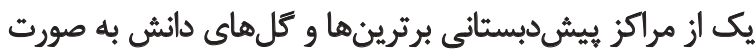

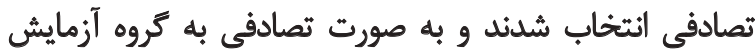

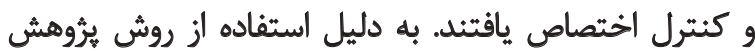

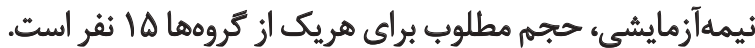

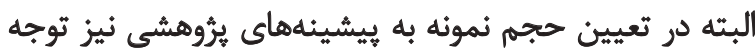

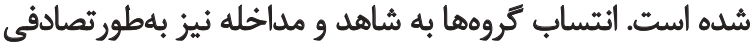


جدول ا. هدف و محتواى جلسات بازىدرماني در كروه آزمايش

\begin{tabular}{|c|c|c|}
\hline محتوا & هدف & جلسات \\
\hline 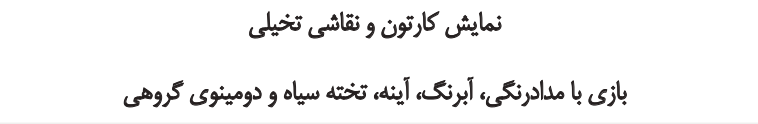 & آشنايع و ترغيب به همكارى و افزايش & $\begin{array}{c}1 \\
1\end{array}$ \\
\hline 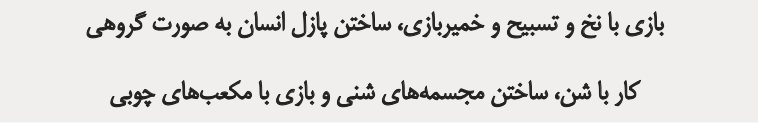 & بهيود مهارتهاى حركتى و خودكترلى & $r$ \\
\hline 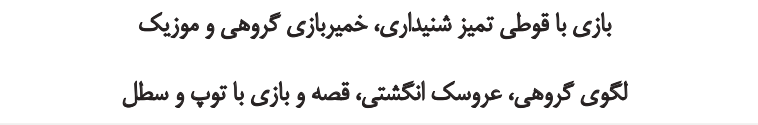 & تقويت همكارى و ابراز هيجان & 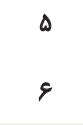 \\
\hline 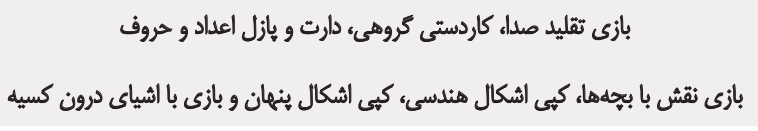 & بهبود مهارت حل مسمله و تصميمكيرى & $\checkmark$ \\
\hline 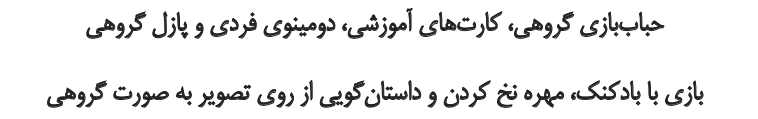 & تقويت فعاليتهاى مشاركتى و ارتباط & 9 \\
\hline خميربازى كروهى، توبهبازى كروهى و ساختن داستان & أكاهى از نشانهانهاى رفتارى و يادكيرى & 11 \\
\hline
\end{tabular}

توانبخننى

شماره ا ا رائه شده است. اين برنامه با استفاده از كتابهاى كليات

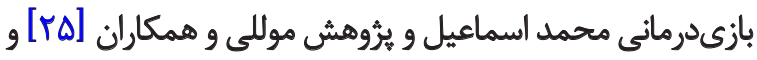

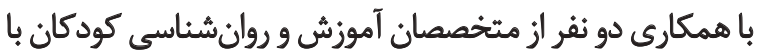

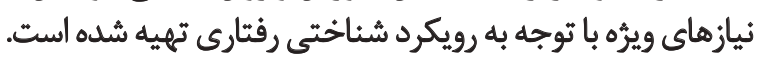
جلسات بازىدرمانى مبتنى بر رويكرد شناختى رفتارى

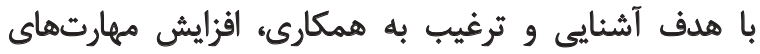

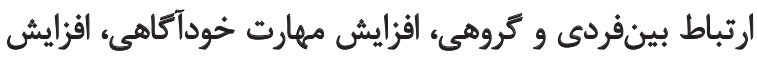

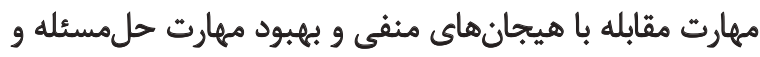

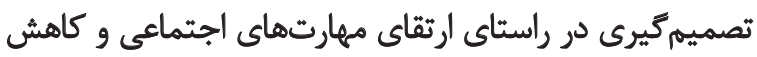

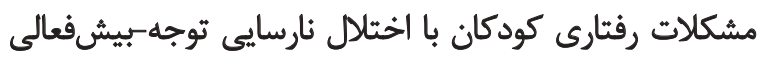

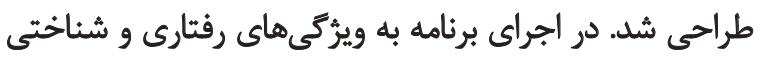

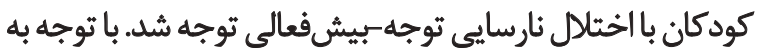

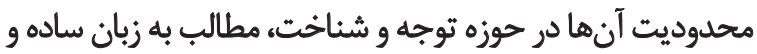

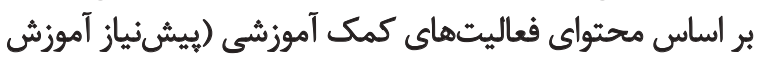

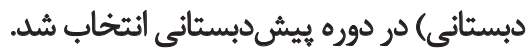

در جلسه اول، درمانكر قوانين و فعاليتهاى جلسهان باني

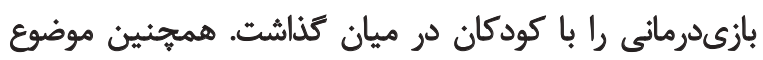

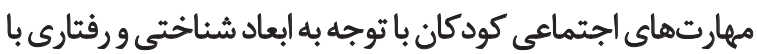

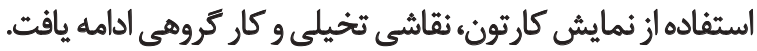

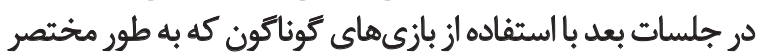

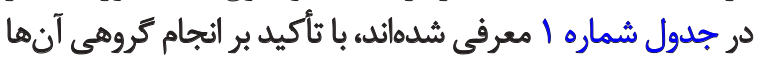

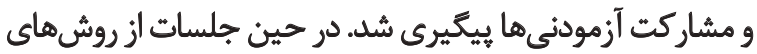

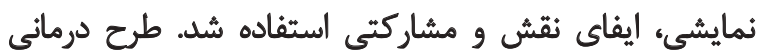

ويره دانشآموزان بيشدبستانى استفاده شد. اين مقياس شامل

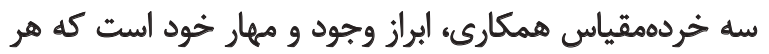

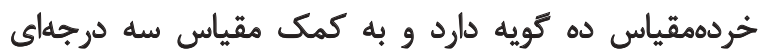

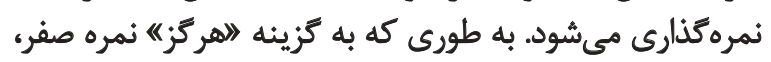

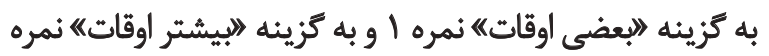

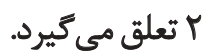

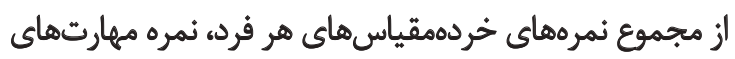

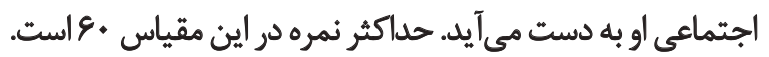

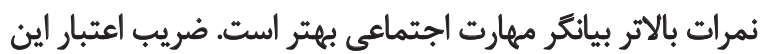

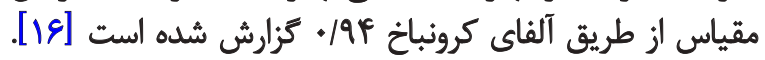

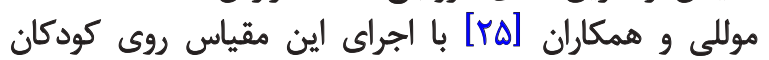

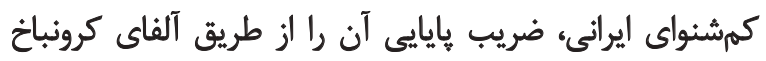

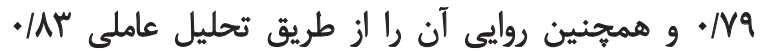

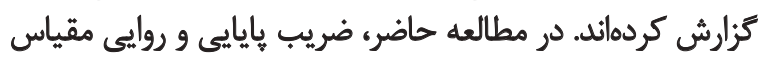

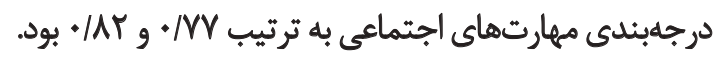
در اولين مرحله يُؤهش، يرسشنامه مشكلات رفتارى و

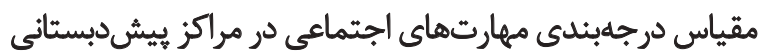

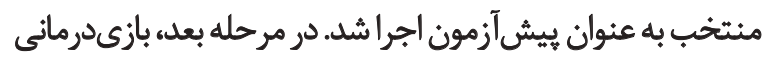

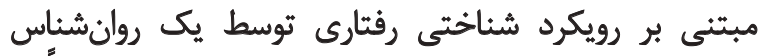

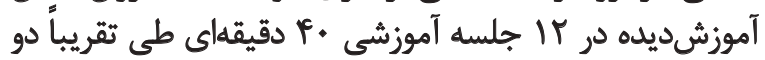

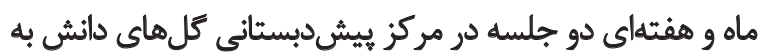

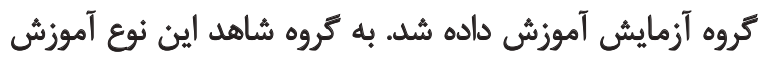

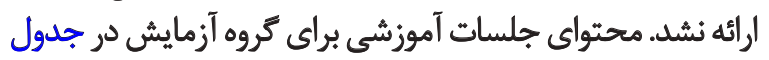


اجتماعى) از دو آزمون آهارى تحليل كوواريانس تكمتيغيرى و

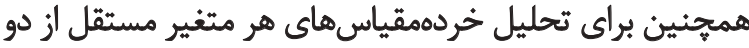
آزمون آمارى تحليل كوواريانس ختئدمثغيرى استفاده شد. براى تعيين تأثير بازىدرمانى مبتنى بر مدل شناختي رفتاري

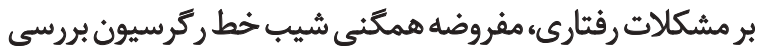

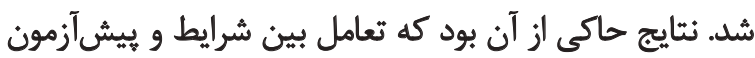

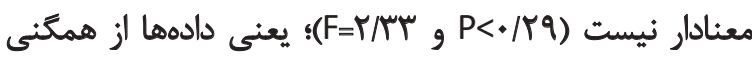

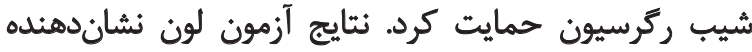

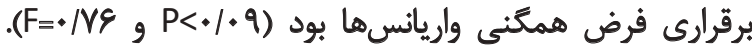

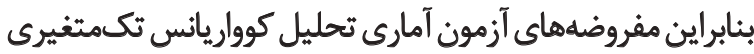

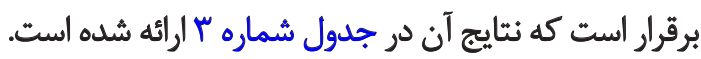
با توجه به نتايج جدول شماره ऍا، كروه اثر معنادارى بر نمرات

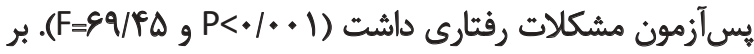

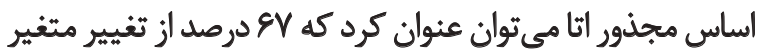

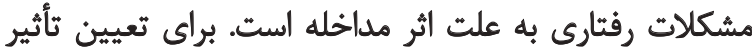

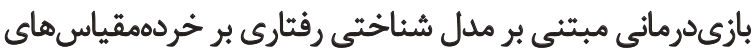

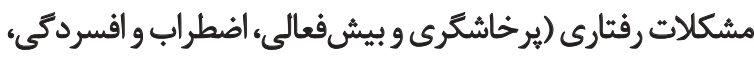

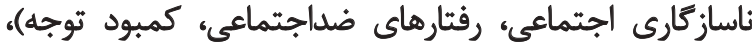

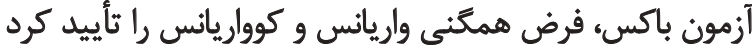

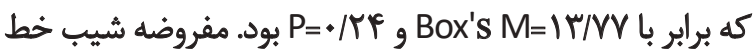
ركرسيون براى متغيرها و خطى بودن رابطه متغيرها برقرار بود.

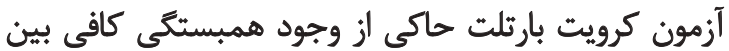

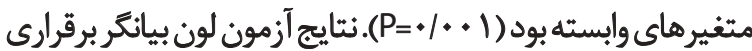

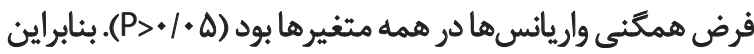

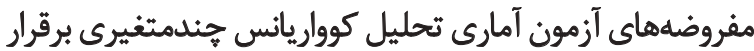

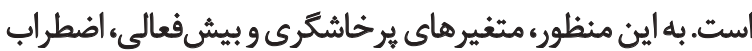

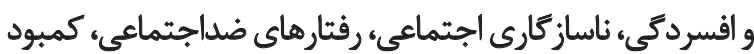

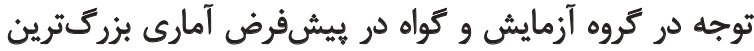

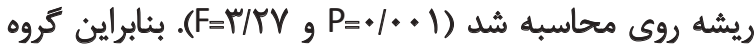

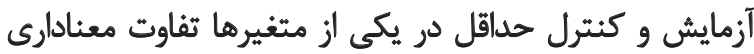

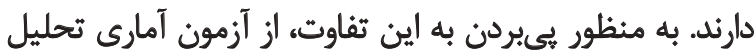

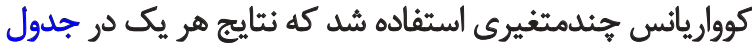
شماره f آمده است.

با توجه به نتايج جدول شماره F، گروه اثر معنادارى بر نمرات

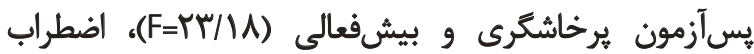

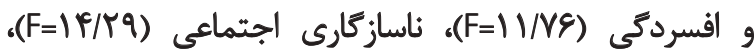

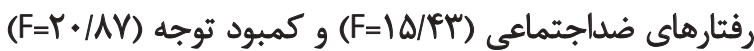

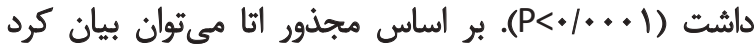

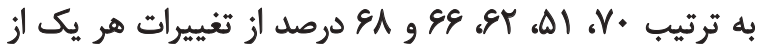

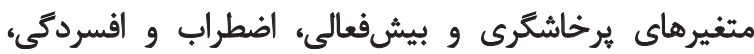

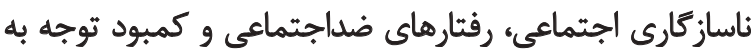

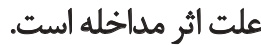

جلسات روى افزايش خودكنترلى كودى، آكاهازى كودكان

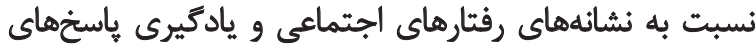

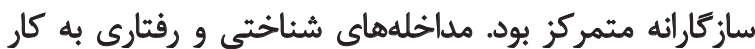

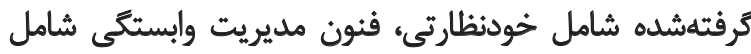

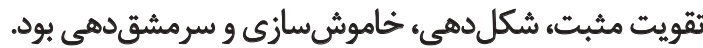
در پايان جلسات آموزش بازى برمانى مبتنى بر مدل شناختى

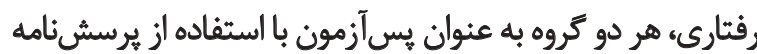

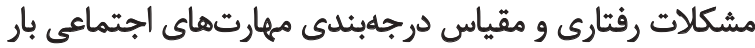

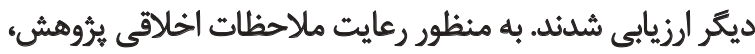

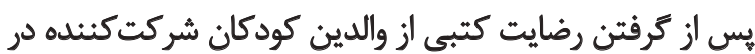
ثرُوهش و جلب همكارى كودكان، يُروهش صورت كر كرفت به مسئولان مراكز و والدين كودكان شركث كننده در اين

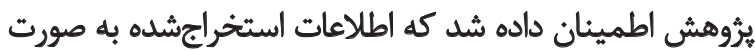

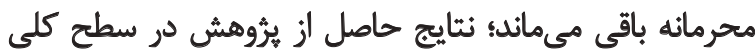

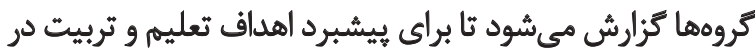

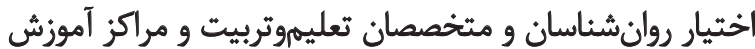

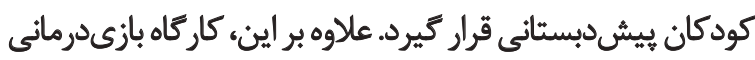

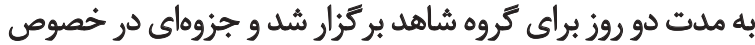

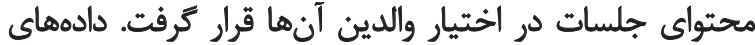

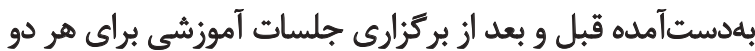

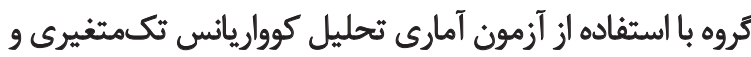
تحليل كوواريانس جندمثتغيرى تحليل شدا أماري

ياقتهها يافتههاى توصيفى بيانكَر سن آزمودنىها در كروه آزمايش

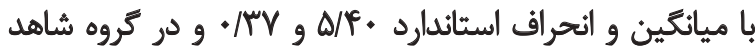

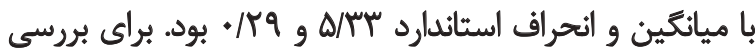

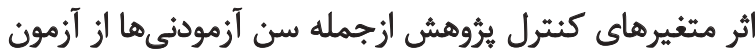

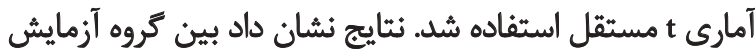

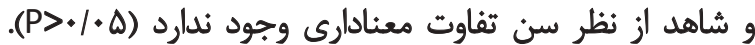

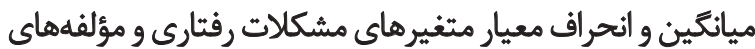

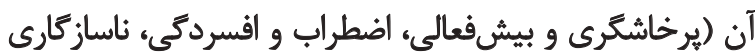

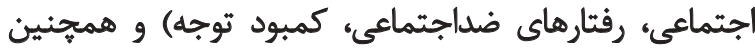
مهارتهاي اجتماعي و مؤلفههاي آن (مشاركت، ابراز وجئ وجوده، مهار

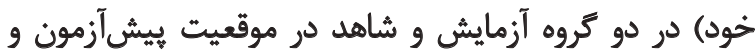
بس آزمون در جدول شماره بار ارائه شده است.

ميانكين و انحراف استاندارد نمرات بيش آزمون و وِيسآزمون

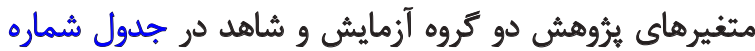

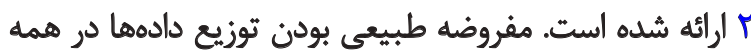

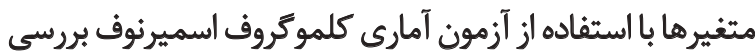

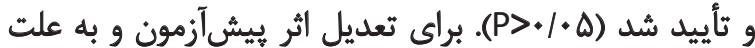

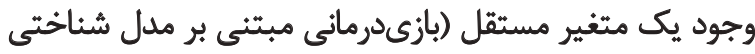

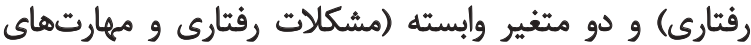


جدول r. ميائكين و انحرافمعيار مشكلات رفتارى و مهارتهاى اجتماعى كروه آزمايش و شاهد

\begin{tabular}{|c|c|c|c|c|c|c|c|}
\hline \multicolumn{3}{|c|}{ كروه شاهد } & \multicolumn{3}{|c|}{ كروه آزمايش } & \multirow{2}{*}{ موقعيت } & \multirow{2}{*}{ مثغيرها } \\
\hline نرماليتى & افحرافمعيار & مياتكين & نوماليتى & اتحرافمعيار & مياتكين & & \\
\hline.$/ T$ & VTE & $\Delta / \pi t$ & . & $1 / N$ & $\Delta / \pi Y$ & ييش آزمون & \multirow[b]{2}{*}{ يرخاشكرى و ييشفعالى } \\
\hline $.1+1$ & $M$ & $\Delta / / V$ & .119 & $1 / * 1$ & $P / 11$ & يس أزهون & \\
\hline.$/ 1 Y$ & VTA & $r / . r$ &.$/ T$ & V/AY & $r / \bullet 1$ & ييش آزمون & \multirow{2}{*}{ اضطراب و افسردكى } \\
\hline.$/ 11$ & $V \cdot r$ & $m / F$ &.$/ N$ & V/ar & $T / \pi$ & بس آزمون & \\
\hline .119 & $1 / 79$ & F/MT & $\% 1$ & $1 / 79$ & e/Re & ييش آزمون & \multirow{2}{*}{ ثاساز كارى اجتماعى } \\
\hline.$/ 79$ & Wer & $e / \pi$ &.$/ N$ & $M$ & $M / r$ & بيس آزمون & \\
\hline.$\pi$ & W/Y & $p / r q$ &.$/ V$ & V/AV & $\varphi / 4 A$ & ييش آزمون & \multirow{2}{*}{ رقتارهاي ضلاجتماعى } \\
\hline.$/ . Y$ & $M$ & $F / r \Lambda$ &.$/ F i$ & $1 / \cdot 1$ & T/ז & بس آزمون & \\
\hline$+\pi$ & $V / \Delta F$ & $\Delta / V E$ & $+/ r r$ & $1 / 49$ & $\Delta / W$ & ييش آزمون & \multirow{2}{*}{ كميود توجه } \\
\hline$+/ N$ & $1 / \Delta \Delta$ & $P / M$ &.$/ 1 F$ & V/IF & $M / M$ & بـ آزمون & \\
\hline.$/ 19$ & $Y M$ & Tr/gP & $\% v$ & $r / . \varphi^{p}$ & $T Y / M$ & ييش أزمون & \multirow[b]{2}{*}{ مشكلات رفتارى كلى } \\
\hline.$/ 1 P$ & r/eq & $M T / \Delta F$ &.$/ N$ & $r / M r$ & $18 / M$ & بس أزمون & \\
\hline . & P/gI & VIII &.$\pi$ & $r / H)$ & $V / . \varphi$ & ييش آزآمون & \multirow{2}{*}{ مشاركت } \\
\hline 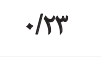 & rlar & Vign &.$M 11$ & 1/91 & W/ar & يس آزّمون & \\
\hline.$/ 19$ & $r / \pi T$ & NTI & .118 & $1 / u$ & NTY & ييش آزأمون & \multirow{2}{*}{ ابراز وجود } \\
\hline.$/ T \Lambda$ & $r / T V$ & NTV & T & $r / \Delta$. & $\mid r / \& 8$ & يسآزمون & \\
\hline.$/ 1 Y$ & $r / \Delta r$ & $v / \cdot 1$ &.$/ 19$ & $r / A)^{F}$ & $8 / 94$ & ييشآزمون & \multirow{2}{*}{ مهار خود } \\
\hline r & $\mathrm{r} / \mathrm{GA}$ & $\mathrm{V} / \mathrm{II}$ &.$M$ & $T / F \Delta$ & $1 . / \Delta T$ & يسآزمون & \\
\hline$+/ 10$ & $r / \bullet A$ & $r T / \pi T$ & $+\pi$ & $m / M V$ & $r T / T^{\circ}$ & ييشآزمون & \multirow{2}{*}{ مهارتهاى اجتماعى كلى } \\
\hline.$/ 1$ & $\mathrm{~T} / \mathrm{TV}$ & $\pi / \cdot \%$ & .1 .9 & r/Ar & $M / N$ & يس آزمون & \\
\hline
\end{tabular}

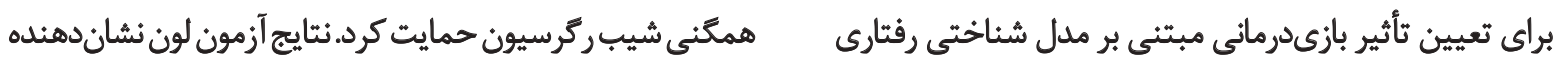

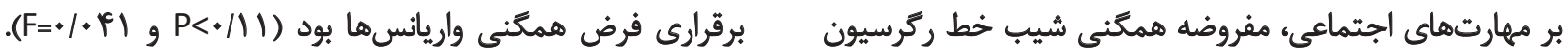

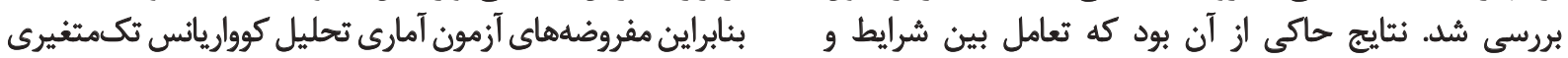

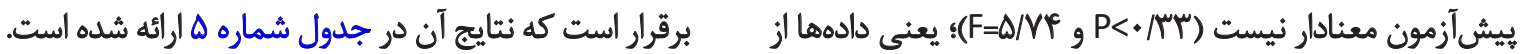

جدول ب.نتايج تحليل كواريانس تكمتغيرى نمره يسآزمون مشكلات رفتارى

\begin{tabular}{|c|c|c|c|c|c|c|c|}
\hline توان آمارى & مجدور اتا & سطح معنادارى & Fسب F F F & ميانكين مجذورات & درجه آزادى & مجموع مجذورات & مثابع تغيير \\
\hline . NS & $\cdot / M$ & $\% / \%$ & $T / A Y$ & $\| T / \Delta \Delta$ & 1 & $\mid r / \Delta \Delta$ & ييش آزمون \\
\hline \multirow[t]{2}{*}{.$/ 99$} & $.18 \mathrm{~V}$ & $\%$ & sq/PD & $\mid P V / g r$ & 1 & IVW/RY & كروه \\
\hline & & & & $r / \Delta q$ & rV & SNAI & خطا \\
\hline
\end{tabular}

توانبخننى 
جدول †. نتايج تفكيكى تحليل كوواريانس جيندمتغيرى براي خردهمقياس هاي مشكلات رفتارى

\begin{tabular}{|c|c|c|c|c|c|c|}
\hline مجذور اتا & سطح معنادارى & Fسبت F F & مياتكين مجذورات & درجه آزادى & مجموع مجذورات & متغيرهاي وابسته \\
\hline \multicolumn{7}{|c|}{ منابع تغيير (كروخ) } \\
\hline.$/ V$ & $+1+\ldots 1$ & $\pi / M$ & ra/rA & 1 & $r a / r \Lambda$ & برخاشكرى و بيش فعالى \\
\hline.$|\Delta|$ & $.10 . .1$ & $11 / v 8$ & |V/9 & 1 & $|Y / q|$ & أضطراب و افسردكى \\
\hline . & $+1+\ldots+1$ & $19 / 49$ & rmige & 1 & rM/ar & ناسازگ كارى اجتماعى \\
\hline .198 & $.1 . .1$ & $\mid W / F T$ & $\mathrm{rA} / \mathrm{Ar}$ & 1 & $r \Delta / A V$ & رفتارهاى ضداجتماعى \\
\hline .181 & $.1 \ldots . .1$ & $r \cdot / A Y$ & $r V / . r$ & 1 & rV/.F & كمبود توجه \\
\hline
\end{tabular}

توانبخننى

جدول ه. نتايج تحليل كوواريائس تكمتغيرى نمره يّآزمون مهارتهاى اجتماعى

\begin{tabular}{|c|c|c|c|c|c|c|c|}
\hline توان أمارى & مجذور اتا & سيطح معثادارى & Fسبث F & ميائكين مجذوراث & 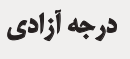 & هجموع مجذورات & مئايع تغيير \\
\hline$\cdot|A|$ &.$/ r A$ & 1.5 & $P / \Delta \Delta$ & ET/TA & 1 & gT/KA & ييش أزمون \\
\hline \multirow[t]{2}{*}{.$/ 9 r$} & .181 & 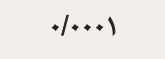 & $\Delta V / W$ & NEVIAT & 1 & AEVIAT & كروه \\
\hline & & & & $\mid Q / \cdot Y$ & rV & $P=\Delta / \Delta P$ & خط \\
\hline
\end{tabular}

توانبخننى

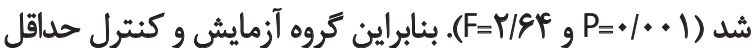

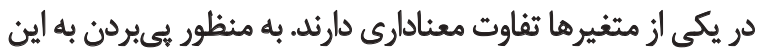

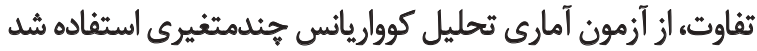
كه نتايج هر يك در جدول شماره آماري كآمده است.

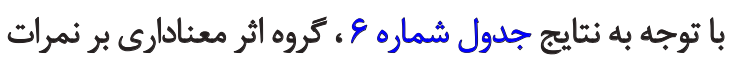

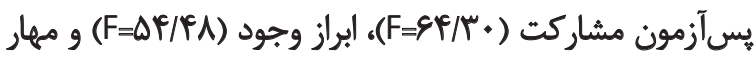

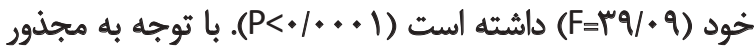

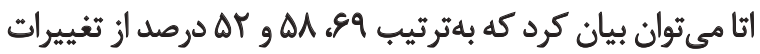

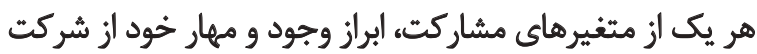

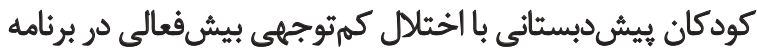

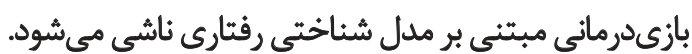

$\Leftrightarrow$

هروهش حاضر با هدف بررسى اثربخشى بازى برمانى مبتنى رئي

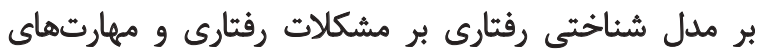

با توجه به نثتايج جدول شماره ه، كروه اثر معنادارى بر نمرات

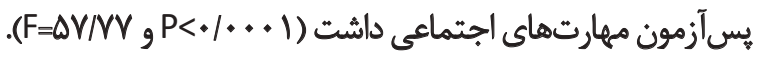

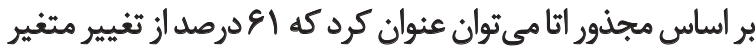

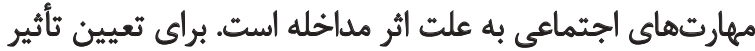

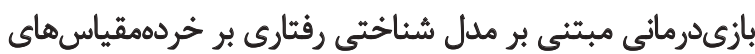

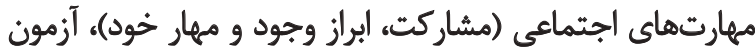

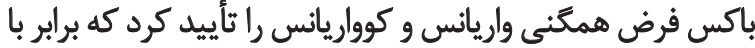

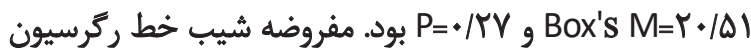

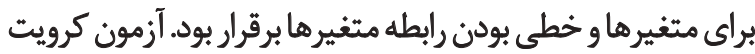

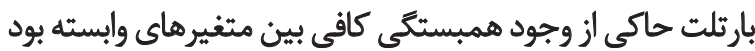

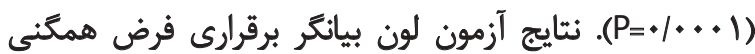

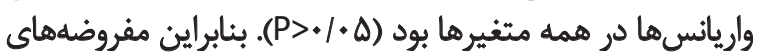

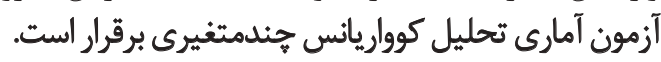
به اين منظور، متغيرهاي مشاركت، ابراز وجود و مهار خود در كروه

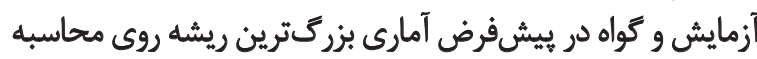

جدول 9. نتايج تفكيكى تحليل كوواريانس جندمتغيرى براي خردهمياسهاى مهارتهاى اجتماعى

\begin{tabular}{|c|c|c|c|c|c|c|c|}
\hline مجذور اتا & سطح معنادارى & Fسبث F ت & مياتكين مجذورات & ورجه أزادى & مجموع مجدورات & متغير هاى وابسته & منابع تغيير \\
\hline .189 & $+\infty+\infty$ & $x / \pi$. & 1891.0 & 1 & $\mid E \& 1.0$ & مشاركت & \\
\hline.$/ \mathrm{AM}$ & $.1 \ldots+1$ & $\Delta F / F A$ & IHM/AF & 1 & Irrater & ابراز وجود & 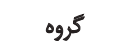 \\
\hline t/Dr & $+1++\infty$ & $r q / q$ & $\Delta V / 9 Y$ & 1 & $\Delta V / a r$ & مهار خود & \\
\hline
\end{tabular}


افسردكى كودكان شركت كنيده در برنامه كاهش يابد.

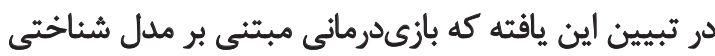

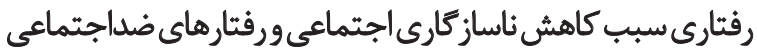

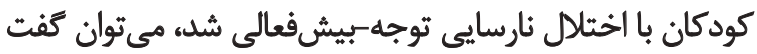

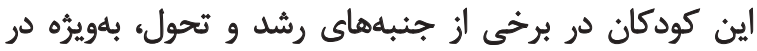

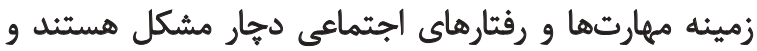

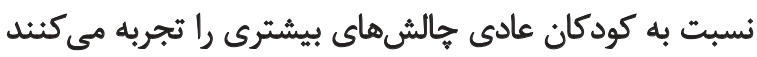

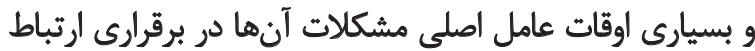

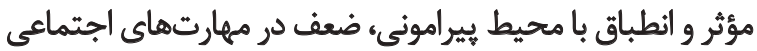

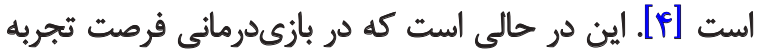

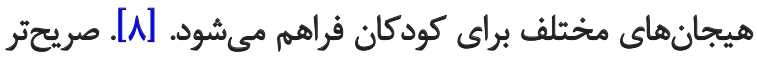

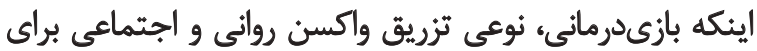

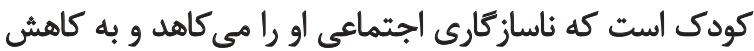

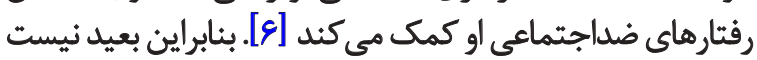

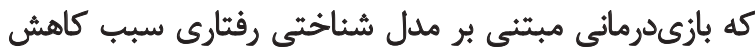

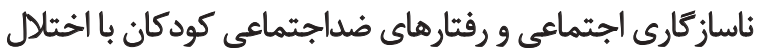
نارسايي توجه-بيش فئمالى شود.

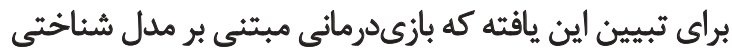

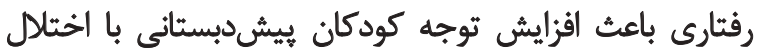

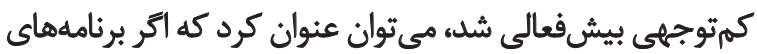

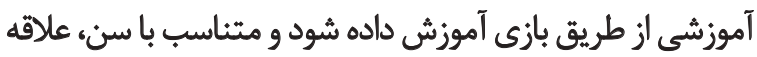

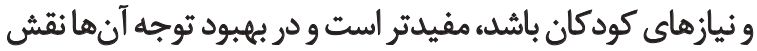

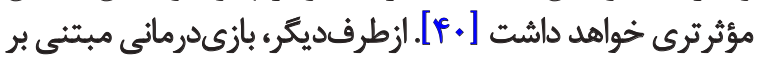

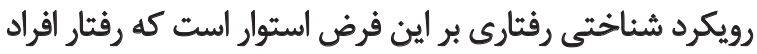

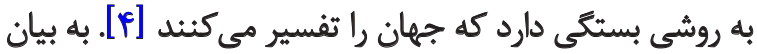

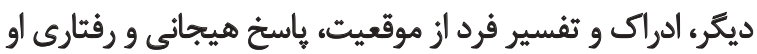

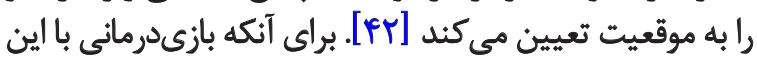

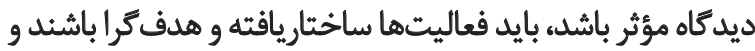

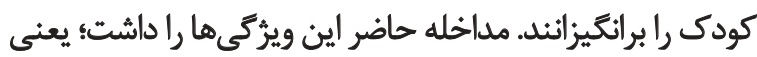

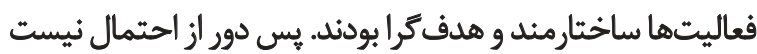
كه باعث كاهش مشكلات توجهى كودكان با با اختلال نارسايتي دوراني توجه-بيش فعالى شود.

بخش ديكرى از نتايج يرؤهش حاضر بيانكر اثربخشى آموزش بردي

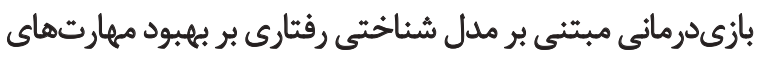

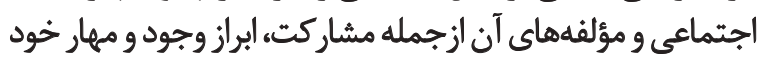

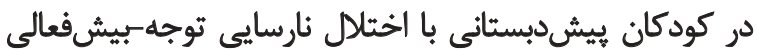

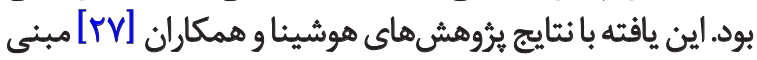

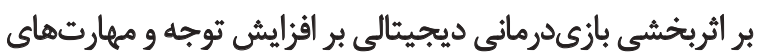

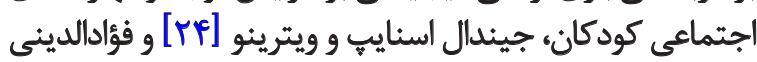

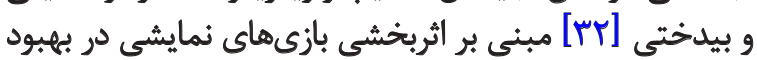

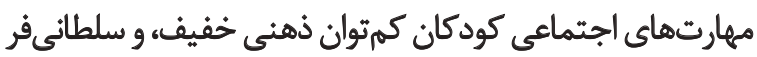

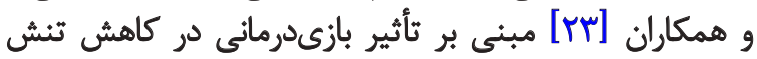

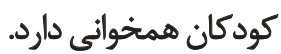

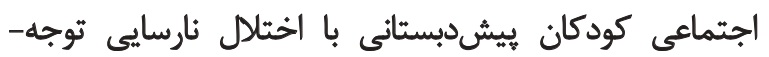

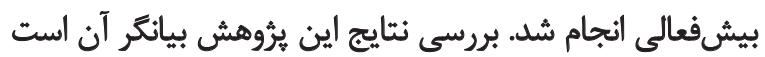

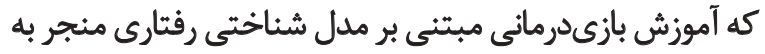

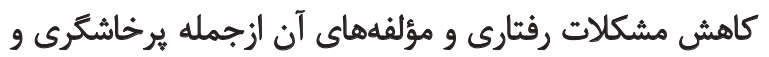

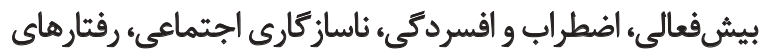

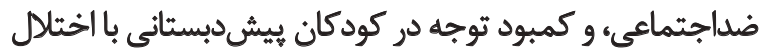

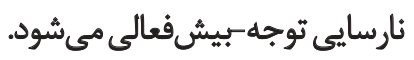

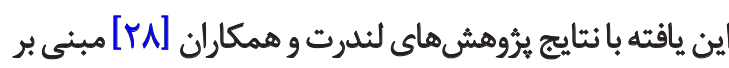

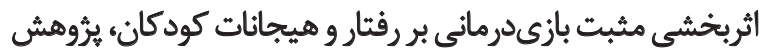

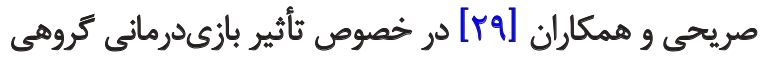

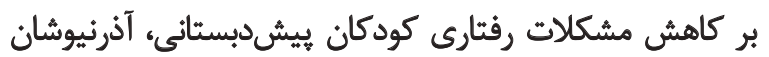

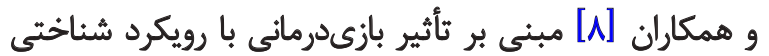

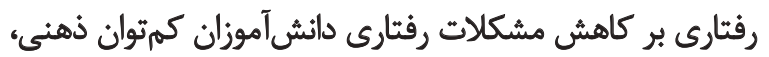

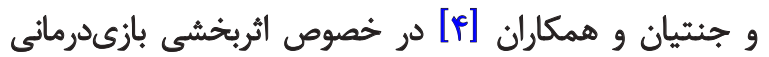
شناختى رفتارى بر كاهش معنادار مشكلات رفتان إنتارى كودكان باري باريان

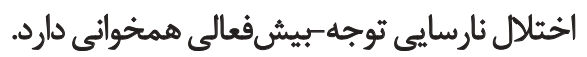

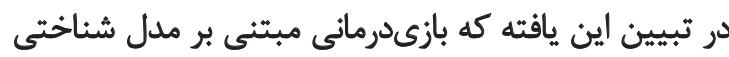

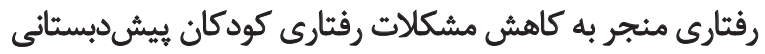

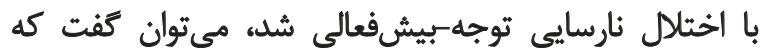

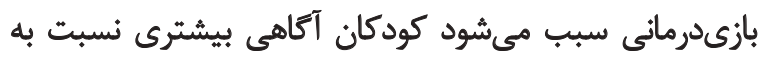

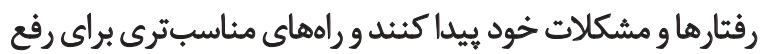

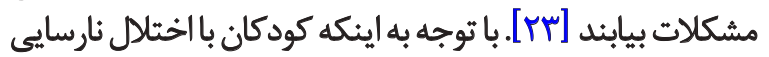

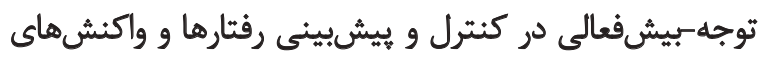

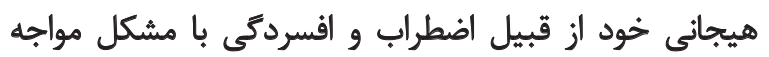

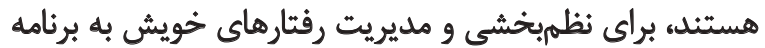

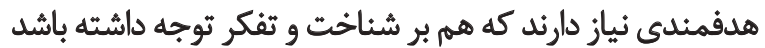

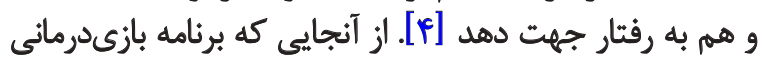

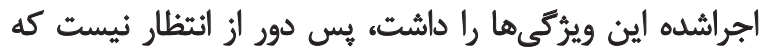
مشكلات رفتارى آزمودنى ها كاهش يابد الدات

در خصوص تبيين دومين يافته يثوهش مبنى بر بر اينكه

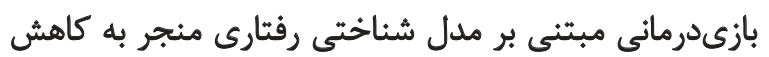

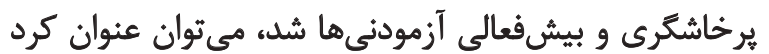

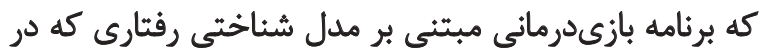

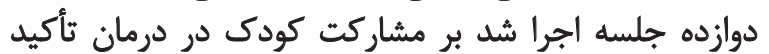

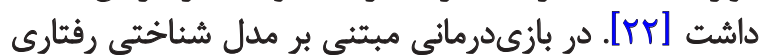

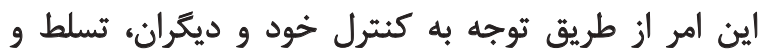

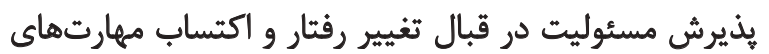

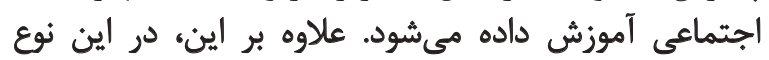

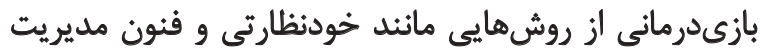

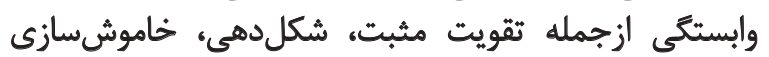

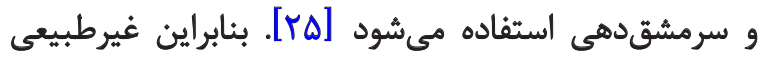

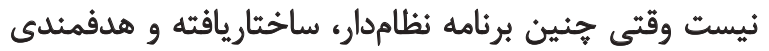

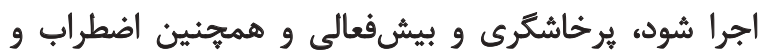


با اختلال كمتوجهى بيشفعالى تأثير قابل توجهى داشته باشد. براى تبيين اين يافته كه بازىدرمانى مبتنى بر مدل شناختي

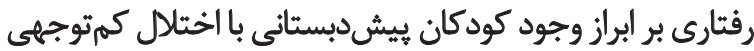

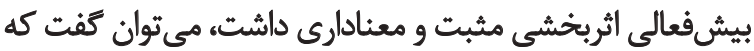

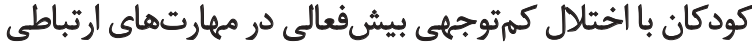

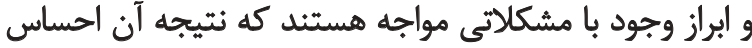

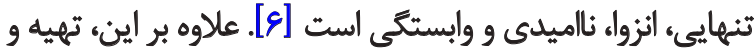

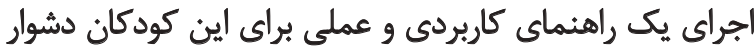

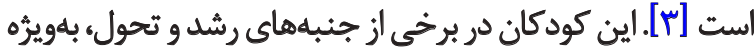

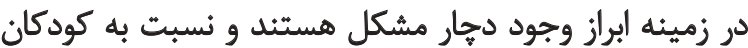

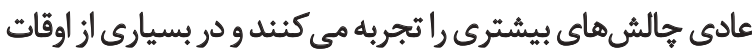

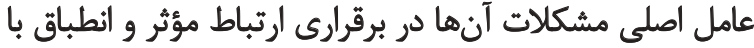

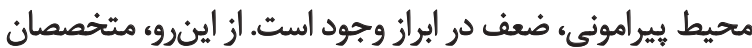

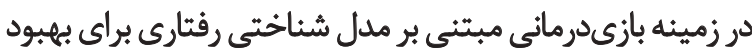

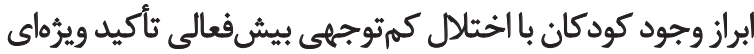

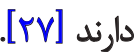

در راستاى تبيين آخرين يافته بروهش حاضر مبنى بر اينكه

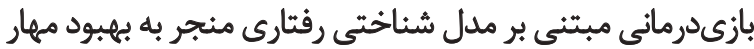

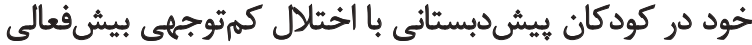

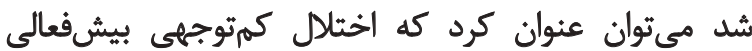

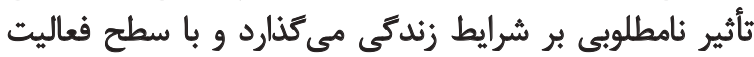

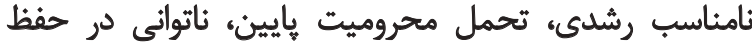
توجه، تكانش كرى و وفتارهاى آشفته همراه است و كودكان بان بانيا

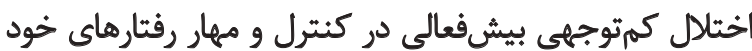

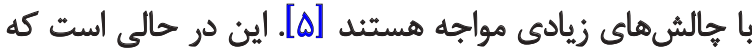

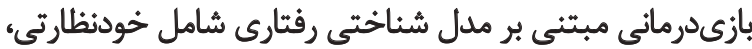

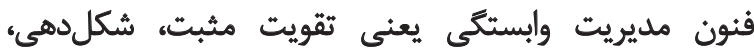

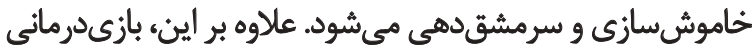

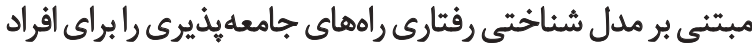

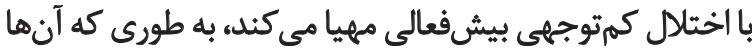

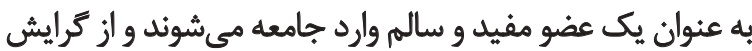

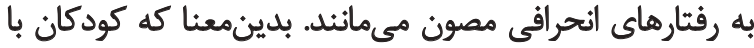

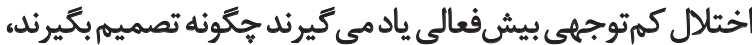

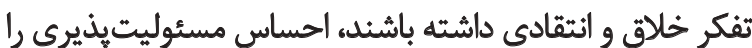

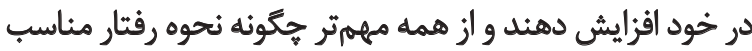

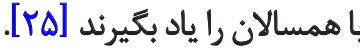

همجنين كودكان از طريق مشاركت در اين نوع بازىدرماثى

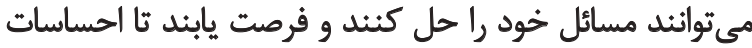

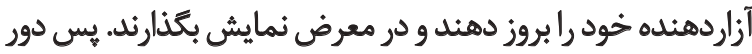

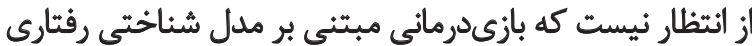

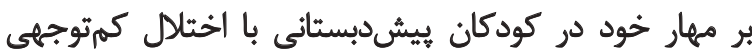
بيشفعالى تأثير قابل توجهى داشته باشد. ئردان
همجئين با نتايج ثروهشهاى آذرنيوشان و همكاران

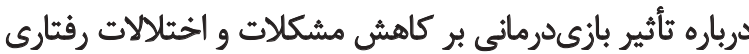

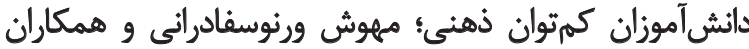

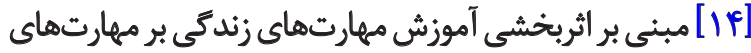

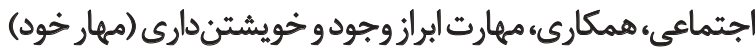

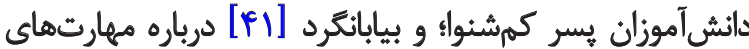

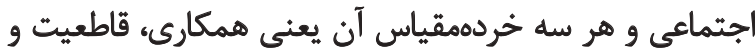

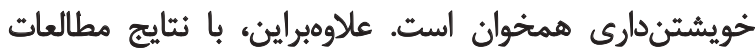

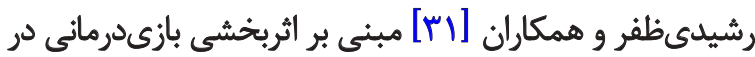
بهبود مهارتهاى اجتماعى در كودكان همسو است.

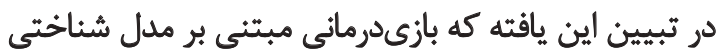

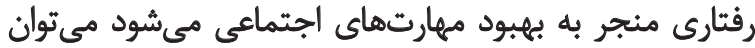

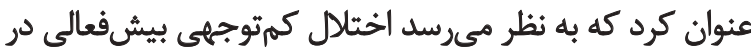

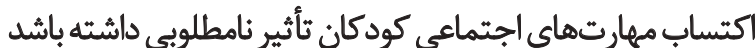

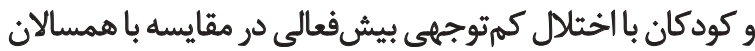

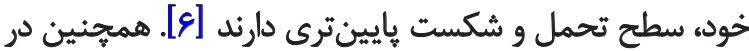

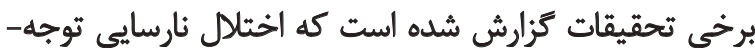

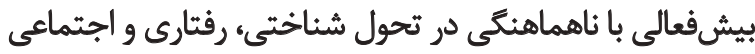

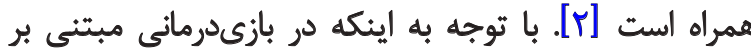

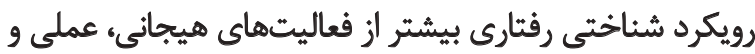

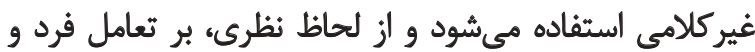

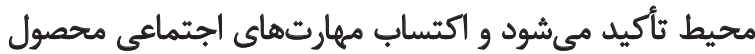

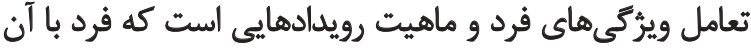

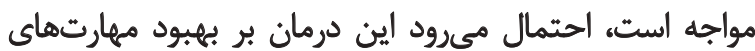

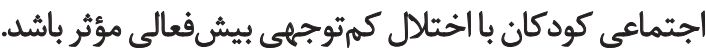

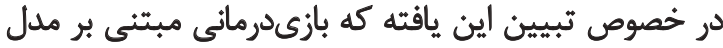

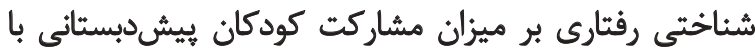

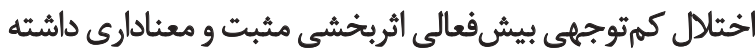

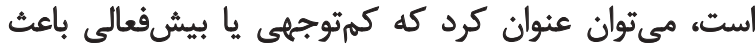

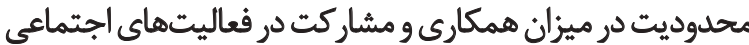

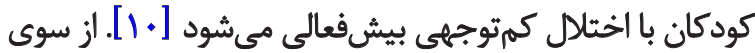

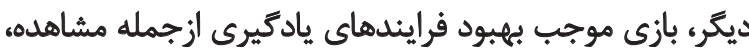

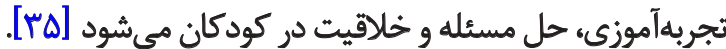
نكته ديكر اينكه تجربه هيجانهاي مختلف در بازئ دادرمانى

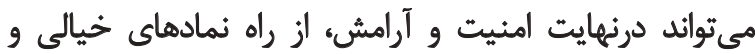
اسباببازىها بيان شود. بازى روشيى است كه در در آن، كودى آنى

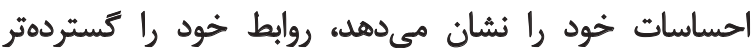
مى كند، تجربياتش را مىنماياند، آرزوهايش را را آشكار مى رانسازد

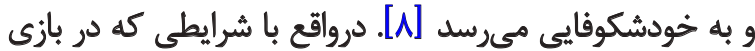

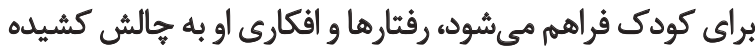

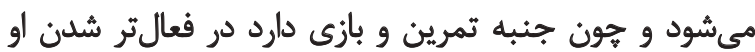

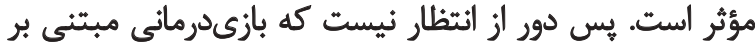

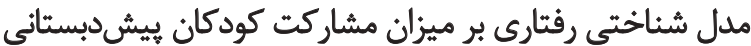


درنهايت، موجب كاهش مشكلات رفتارى و بهببود رفتارهاى

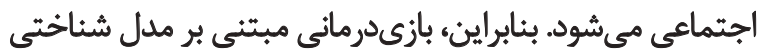

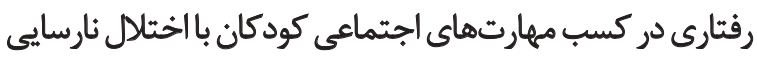

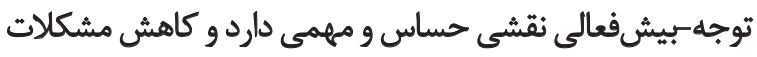

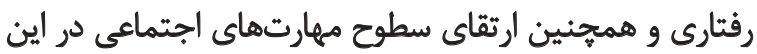
كودكان دور از انتظار نخواهد بودي

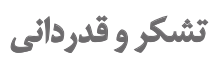

وبدينوسيله از مديران و مربيان مراكز بيش دانستانى برترينها

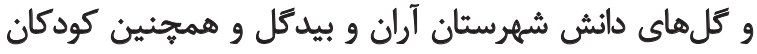

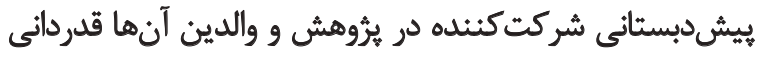
مي مشود. يروهش حامى مالى ندارد.
اين يُؤوهش با محدوديتهايى مواجه بوده است كه عبارتند ازئ

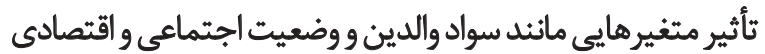

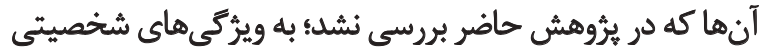

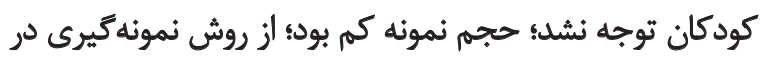

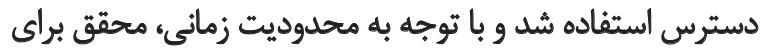

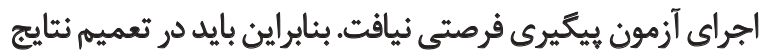

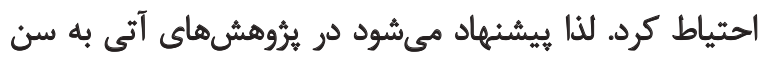

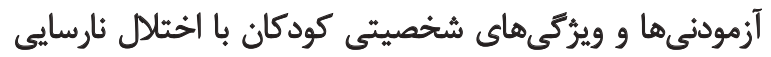

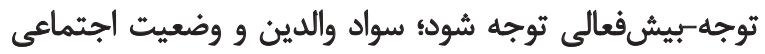

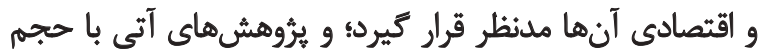

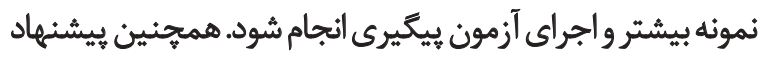

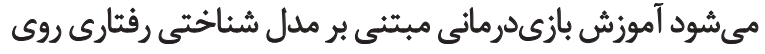

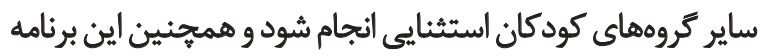

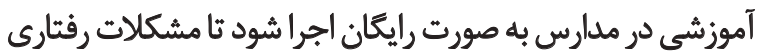
كودكان كمتر شود و مهارتهاى اجتماعى اليكان ارتقا يابد.

\section{تثيجهإنيرى}

بهطوركلى نتايج يروهش حاضر نشان داد آموزش بازى مدرمانى

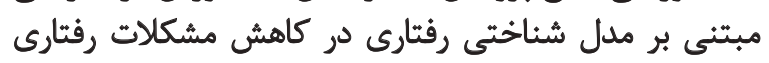

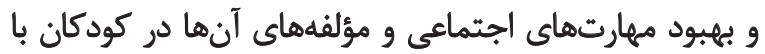

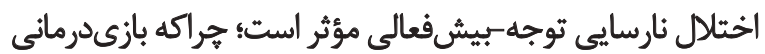

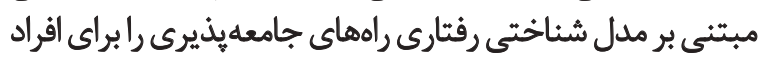

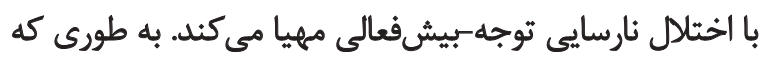

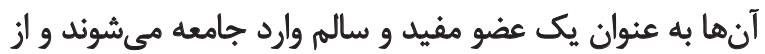

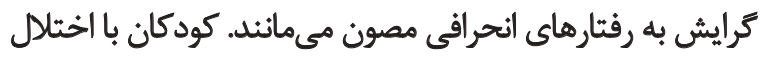

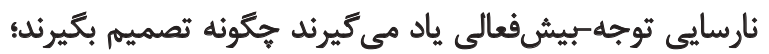

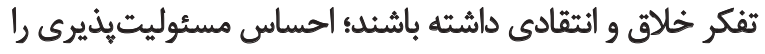

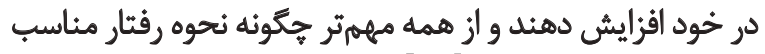

با همسالان را ياد بخيرند [11\%]

علاوهبراين، بخش عمدهاي از مشكلات كودكان با اختلال

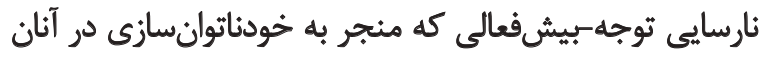

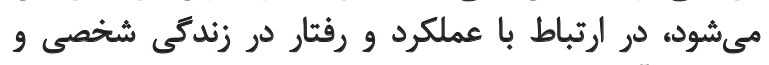

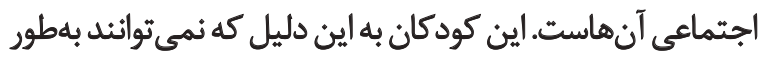

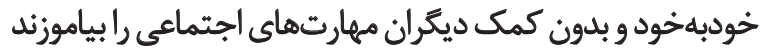

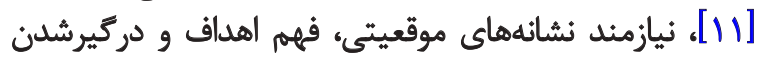

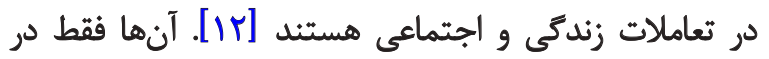

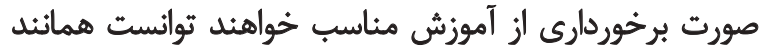

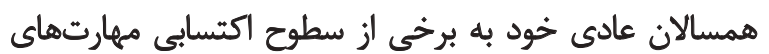

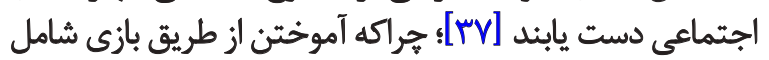

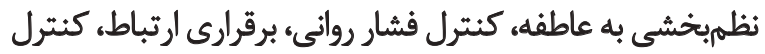

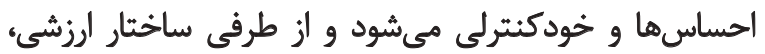

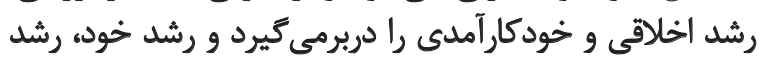

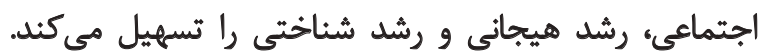




\section{References}

[1] Kirk S, Gallagher G, Coleman MR. Educating exceptional children. New York: Elsevier; 2015.

[2] Malka M, Marshall HR. Mothers of children with LD and ADHD: Empowerment through Online communication. Journal of Special Education Technology. 2009; 24(1):39-49. [DOI:10.11 $77 / 016264340902400104]$

[3] Anastopoulos AD, DuPaul GJ, Weyandt LL, Morrissey-Kane E, Sommer JL, Rhoads LH, et al. Rates and Patterns of Comorbidity Among First-Year College Students With ADHD. Journal of Clinical Child \& Adolescent Psychology. 2018; 47(2):236-47. [DO I:10.1080/15374416.2015.1105137] [PMID]

[4] Janatian S, Nouri A, Shafti A, Molavi H, Samavatyan H. [Effectiveness of play therapy on the bases of cognitive behavior approach on severity of symptoms of Attention Deficit/Hyperactivity Disorder (ADHD) Among primary school male students aged 9-11(Persian)]. Journal of Research in Behavioural Sciences. 2008; 6(2):109-116.

[5] Ashori M, Jalil-Abkenar SS. [Students with special needs and inclusive education (Persian)]. Tehran: Roshd-e Farhang; 2016

[6] Pourmohammadreza-Tajrishi M, Ashori M, Jalil-Abkenar SS, Behpajooh A. [The effectiveness of response inhibitation training on the working memory in students with attention deficit/ hyperactivity disorder (Persian)]. Archives of Rehabilitation. 2015; 15(4):12-20.

[7] Esbjørn BH, Normann N, Christiansen BM, Reinholdt-Dunne, ML. The efficacy of group metacognitive therapy for children (MCT-c) with generalized anxiety disorder: An open trial. Journal of Anxiety Disorders. 2018; 53:16-21. [DOI:10.1016/j. janxdis.2017.11.002] [PMID]

[8] Azarnioshan B, Beh-Pajooh A, Ghobary Bonab B. [The effectiveness of cognitive behavior-based play therapy on the behavioral problems among primary students with intellectual disabilities (Persian)]. Journal of Exceptional Children. 2012; 12(2):5-16.

[9] Bulgan C, Ciftci A. Psychological adaptation, marital satisfaction, and academic self-efficacy of international students. Journal of International Students. 2017; 7(3):687-702.

[10] Ros R, Graziano PA. Social functioning in children with or at risk for attention deficit/hyperactivity disorder: A meta-analytic review. Journal of Clinical Child \& Adolescent Psychology. 2018; 47(2):213-35. [DOI:10.1080/15374416.2016.1266644] [PMID]

[11] Hallahan DP, Kauffman JM, Pullen PC. Exceptional learners: An introduction to special education. New York: Pearson; 2015.

[12] Babinski DE, Mills SL, Bansal PS. The effects of behavioral parent training with adjunctive social skills training for a preadolescent girl with ADHD and borderline personality features. Clinical Case Studies. 2017; 17(1):21-37. [DOI:10.1177/1534650117741707]

[13] Afrooz GA, Ashori M. [Psychology of behavior management of restless and hyperactive children (Persian)]. Tehran: University of Tehran; 2015.

[14] Mahvashevernosfaderani A, Adibsereshki N, Movallali G. [The effectiveness of life skills training on the social skills of hearing impaired secondary school students in inclusive schools (Per- sian)]. Journal of Research on Rehabilitation Sciences. 2012; $8(3): 477-88$.

[15] Altun I. The perceived problem solving ability and values of student nurses and midwives. Nurse Education Today. 2003; 23(8):575-84. [DOI:10.1016/S0260-6917(03)00096-0]

[16] Jalilabknar SS, Ashoori M, Afrooz GA. [The effect of social behaviors training on improvement of the social skills of adolescents with intellectual disability (Persian)]. Archives of Rehabilitation. 2013; 14(3):31-40.

[17] Behroz-Sarcheshmeh S, Karimi M, Mahmoudi F, Shaghaghi P, Jalil-Abkenar SS. Effect of training of life skills on social skills of high school students with intellectual disabilities. Practice in Clinical Psychology. 2017; 5(3):177-86. [DOI:10.18869/acadpub. jpcp.5.3.177

[18] Roderick DOH, Keith CR, John DKL. Promoting social com munication in a child with specific language impairment. Communication Disorders Quarterly. 2015; 37(4):199-210. DOI: $10.1177 / 1525740115595346$

[19] Frank MG. Social skills training with handicapped children: A review. Review of Educational Research. 1981; 51(1):139-76. [DOI:10.3102/00346543051001139]

[20] Sibley MH, Coxe SJ, Campez M, Morley C, Olson S, HidalgoGato $\mathrm{N}$, et al. High versus low intensity summer treatment for ADHD delivered at secondary school transitions. Journal of Clinical Child \& Adolescent Psychology. 2018; 47(2):248-65. [D OI:10.1080/15374416.2018.1426005] [PMID]

[21] Danielson ML, Bitsko RH, Ghandour RM, Holbrook JR, Kogan MD, Blumberg SJ. Prevalence of parent-reported ADHD diagnosis and associated treatment among U.S. children and adolescents, 2016. Journal of Clinical Child \& Adolescent Psychology. 2018; 47(2):199-212. [DOI:10.1080/15374416.2017.141786 0] [PMID]

[22] Jayne KM, Ray DC. Child-centered play therapy as a comprehensive school counseling approach: Directions for research and practice. Person-Centered \& Experiential Psychotherapies. 2016; 15(1):5-18. [DOI:10.1080/14779757.2015.1132757]

[23] Soltanifar A, Gafarzade F, Modares M, Mokhber N, Rezaei A. [The efficacy of developmental attachment-based play therapy on developmental trauma disorder symptoms in children from 3 to 9 years old (Persian)]. Mental Health Journal. 2012; 14(3):260-8.

[24] Jindal-Snape D. Vettraino E. Drama techniques for the enhancement of social-emotional development in people with special needs: review of research. International Journal of Special Education. 2007; 22(1):107-17.

[25] Movallali G, Jalil-Abkenar SS, Ashouri M. [The efficacy of group play therapy on the social skills of pre-school hearing-impaired children (Persian)]. Archives of Rehabilitation. 2015; 16(1):76-85.

[26] Akbari B, Rahmati F. [The efficacy of cognitive behavioral play therapy on the reduction of aggression in preschool children with attention-deficit/hyperactivity disorder (Persian)]. Quarterly Journal of Child Mental Health. 2015; 2(2):93-100.

[27] Hoshina A, Horie R, Giannopulu I, Sugaya M. Measuremen of the effect of digital play therapy using biological information. 
Procedia Computer Science. 2017; 112:1570-9. [DOI:10.1016/j. procs.2017.08.104]

[28] Landreth GL, Ray DC, Bratton SC. Play therapy in elementary schools. Psychology in the Schools. 2009; 46(3):281-89. [DOI:10.1002/pits.20374]

[29] Sarihi N, Pournesaei GS, Nikakhlagh M. [Effectiveness of group play therapy on behavior problems in preschool children (Persian)]. Journal of Analytical-Cognitive Psychology. 2015; 6(23):35-41.

[30] Ghyasizadeh M. [The effect of play therapy with a cognitive approach - behavioral Mayknbam reduce shyness and social withdrawal Malekshahy city school students (Persian)]. Journal of Ilam University of Medical Sciences. 2013; 21(6):96-105.

[31] Rashidi-Zafar M, Janbozorgi M, Shaghaghi F. Positive social behavior efficacy of play therapy on progress of pre-school children (Persian)]. Journal of Behavioral Sciences. 2012; 6(1):69-77.

[32] Foadodini M, Beydokhti M. [The effect of drama therapy base on social skill adjusting behavior of mental retarded girls $(\mathrm{IQ}=55$ 70 , 14-30 years old) (Persian)]. Journal of Research in Rehabilitation Sciences. 2012; 8(5):913-8.

[33] Fridman M, Banaschewski T, Sikirica V, Quintero J, Chen KS. Access to diagnosis, treatment, and supportive services among pharmacotherapy-treated children/adolescents with ADHD in Europe: Data from the Caregiver Perspective on Paediatric ADHD survey. Neuropsychiatric Disease and Treatment. 2017; 13:947-58. [DOI:10.2147/NDT.S128752]

[34] Mora L, Sebille K, Neill L. An evaluation of play therapy for children and young people with intellectual disabilities. Research and Practice in Intellectual and Developmental Disabilities, 2018; 1-14. [DOI:10.1080/23297018.2018.1442739]

[35] Ghodousi N, Sajedi F, Mirzaie H, Rezasoltani P. [The effectiveness of cognitive-behavioral play therapy on externalizing behavior problems among street and working children (Persian)]. Iranian Rehabilitation Journal. 2017; 15(4):359-66. [DOI:10.29252/ nrip.irj.15.4.359]

[36] Shah Rafati F, Pourmohamadreza M, Pishyareh E, Mirzaei H, Biglarian A. [Effectiveness of group play therapy on the communication of 5-8 years old children with high functioning autism (Persian)]. Archives of Rehabilitation. 2016; 17(3):200-211.

[37] Gowdini, R, Pourmohamdreza-Tajrishi M, Tahmasebi S, Biglarian A. [Effect of emotion management training to mothers on the behavioral problems of offspring: Parents' view (Persian)]. Archives of Rehabilitation. 2017; 18(1):13-24. [DOI:10.21859/ jrehab-180113]

[38] Rutter M, Cox A, Tupling C, Berger M, Yule W. Attainment and Adjustment in Two Geographical Areas: I--The Prevalence of Psychiatric Disorder. The British Journal of Psychiatry. Br J Psychiatry, 1975; 126:493-509. [DOI:10.1192/bjp.126.6.520] [PMID]

[39] Tavakkolizadeh J, Bolhari J, Mehryar AH, Dezhkam M. [Epidemiology of attention deficit and disruptive behaviour disorders in elementary school children of Gonabad town, north east Iran (1996-1997) (Persian)]. Iranian Journal of Psychiatry and Clinical Psychology. 1997; 3(1):40-52.
[40] Kristen LM, et al. A review of social problem-solving interventions: Past findings, current status, and future directions. Review of Educational Research. 2016; 87(1):71-102. [DOI: 10.3102/0034654316652943]

[41] Biabangard E. [A comparison of social skills between blind, deaf and normal high school female student in Tehran (Persian)]. Journal of Exceptional Children. 2005; 5(1):55-68.

[42] Jalil-Abkenar SS, Ashouri M, Pourmohammadreza-Tajrishi M. [Investigation of the effectiveness social competence instruction on the adaptation behavior in male students with intellectual disability (Persian)]. Archives of Rehabilitation. 2013; 13(1):104-13.

[43] Movallali G, Tayebi ramin Z, Rezaee madani M. [Effectiveness of group logo therapy on increasing the quality of the mothers' life of hearing impaired children (Persian)]. Social Welfare. 2016; 16(61): 221-42.

[44] Bahrami B, Dolatshahi B, Pourshahbaz A, Mohammadkhani P. PParenting style and emotion regulation in mothers of preschool children. Journal of Practice in Clinical Psychology. 2018; 6(1):38. [DOI:10.29252/nirp.jpcp.6.1.3] 